\title{
Determination of Interproton Distances from NOESY Spectra in the Active Site of Paramagnetic Metalloenzymes: Cyanide-Inhibited Horseradish Peroxidase
}

\author{
Marco Sette, ${ }^{\dagger, 8}$ Jeffrey S. de Ropp, ${ }^{\ddagger}$ Griselda Hernandez, ${ }^{\dagger}$ and Gerd N. La Mar ${ }^{\star, \dagger}$ \\ Contribution from the Department of Chemistry and Nuclear Magnetic Resonance Facility, \\ University of California, Davis, California 95616
}

Received January 11, 1993

\begin{abstract}
Two dimensional (2D) nuclear Overhauser effect (NOE) or NOESY experiments are performed on cyanideinhibited horseradish peroxidase in order to assess the prospects for obtaining quantitative interproton distances for the hyperfine shifted and paramagnetically relaxed active site signals in an intermediate sized ( $\sim 44 \mathrm{kDa})$ paramagnetic metalloenzyme. This protein represents an ideal test case for such experiments because a series of structurally defined proton pairs on the heme and axial $\mathrm{His} 170$ have been previously assigned. The relaxation properties of hyperfine shifted signals relevant to the experimental setup of 2D experiments and interpretation of both 1D and 2D NOE data are also investigated. NOESY spectra as a function of mixing time show that quantitative rise curves can be obtained that clearly differentiate between primary and secondary NOEs even among the most strongly relaxed protons, but this requires very short mixing times in the range $0.5-3.0 \mathrm{~ms}$. The sensitivity of the weak cross peaks at these short mixing times is improved by the relatively rapid pulse repetition rate and concommitant increase in the number of scans allowed by the rapid relaxation of active site protons. The paramagnetic relaxation influence, as well as the size of the protein, results in rise curves that are linear to only $1.5 \mathrm{~ms}$ for geminal protons and to only $3-5 \mathrm{~ms}$ for more weakly dipolar coupled proton pairs. However, the cross peak intensities in the linear region are shown to yield cross relaxation rates and internuclear distances for a series of assigned and orientationally invariant proton pairs that are in good agreement with their known distances. The patterns of NOESY rise curves are used both to determine the orientations of one propionate and both vinyl groups relative to the heme and to show that the axial His exhibits an orientation relative to its helix that is similar but not identical to that in crystallographically characterized cytochrome $c$ peroxidase. Selective and nonselective $1 D$ as well as $2 \mathrm{D}$ selective relaxation rate measurements for hyperfine shifted signals show that only selective or intrinsic relaxation rates can be used to optimize the setup of NOESY experiments and interpret 1D NOE data. The results of the study indicate that NOESY spectra can be expected to yield valuable quantitative structural information on the hyperfine shifted active site residues in a variety of cyanide-inhibited heme peroxidases.
\end{abstract}

\section{Introduction}

2D NMR can provide both the resonance assignments and the interproton distances that allow the determination of the solution molecular structure of diamagnetic biopolymers. ${ }^{1,2}$ Similar $2 \mathrm{D}$ NMR studies on analogous paramagnetic systems, particularly near the active site, were originally thought to be impossible, since the paramagnetic-induced relaxation results in substantial diminution of the nuclear Overhauser effect (NOE) and shortcircuits the development of coherence. Recent studies on a variety of paramagnetic metalloproteins, however, have shown that the major 2D experiments are surprisingly effective in detecting both scalar and dipolar connectivities. ${ }^{3}$ To date, however, virtually all studies have emphasized qualitative rather than quantitative aspects of the 2D data. Thus, both COSY and NOESY experiments have been utilized primarily to provide assignments, and few attempts has been made to extract distances from NOESY data on the active site of a paramagnetic protein. In the instances where interproton distances have been determined, ${ }^{4-9}$ the results have relied on the 1D steady-state or truncated NOE.

\footnotetext{
* Address correspondence to this author.

i Department of Chemistry.

t NMR Facility.

On leave from the Department of Chemical Sciences and Technologies, University of Rome, "Tor Vergata".

(1) Wüthrich, K. NMR of Proteins and Nucleic Acids; Wiley \& Sons: New York, NY, 1986.

(2) Robertson, A. D.; Markley, J. L. In Biological Magnetic Resonance; Berliner, L. J., Reuben, J., Eds.; Plenum Press: New York, 1990; Vol. 9, pp 155-176.

(3) La Mar, G. N.; de Ropp, J. S. In Biological Magnetic Resonance; Berliner, L. J., Reuben, J., Eds.; Plenum Press: New York, in press; Vol. 12 (4) Thanabal, V.; de Ropp, J. S.; La Mar, G. N. J. Am. Chem. Soc. 1987 $109,265-272$
}

$0002-7863 / 93 / 1515-5237 \$ 04.00 / 0$
The intensity (volume) of a NOESY cross peak between proton sets $i$ ( $n_{i}$ protons), and $j$ ( $n_{j}$ protons) with intrinsic relaxation rates $\rho_{i}, \rho_{j}$, is given by: ${ }^{10-13}$

$$
a_{i j}=\left(\frac{n_{i} n_{j}}{n_{i}+n_{j}}\right) \frac{V_{0}\left|\sigma_{i j}\right|}{2 D}\left(1-\mathrm{e}^{-2 D \tau_{\mathrm{m}}}\right)\left(\mathrm{e}^{-(R-D) \tau_{m}}\right)
$$

for which the initial term in $\tau_{m}$ represents an exponential buildup due to cross relaxation and the second term in $\tau_{\mathrm{m}}$ represents a decay by a "leakage" rate, $R-D$, where $R=1 / 2\left(\rho_{i}+\rho_{j}\right), \Delta D$ $=\left|\rho_{i}-\rho_{j}\right|, E=\left[(\Delta \mathrm{R})^{2} / 4+\sigma_{i j}{ }^{2}\right]^{1 / 2}$, and $V_{0}=V_{0 i}+V_{0 j}$ is the total magnetization (total intensity or volume of the diagonal peaks for $i, j$ at $\tau_{\mathrm{m}}=0$ ). The cross relaxation rate $\sigma_{i j}$, in the slow motion limit, yields ${ }^{14} r_{i j}$, i.e.:

(5) Thanabal, V.; de Ropp, J. S.; La Mar, G. N. J. Am. Chem. Soc. 1987, 109, 7516-7525.

(6) Banci, L.; Bencini, A.; Bertini, I.; Luchinat, C.; Piccioli, M. Inorg. Chem. 1990, 29, 4867-4873.

(7) Scarrow, R. C.; Pyrz, J. W.; Que, L., Jr. J. Am. Chem. Soc. 1990, 112 , $657-665$

(8) Dugad, L. B.; La Mar, G. N.; Banci, L.; Bertini, I. Biochemistry 1990 $29,2263-2271$.

(9) Cheng, H.; Grohmann, K.; Sweeney, W. J. Biol. Chem. 1990, 265, 12388-12392.

(10) Macura, S.; Huang, Y.; Suter, D.; Ernst, R. R. J. Magn. Reson. 1981, 43, 259-281.

(11) Ernst, R. R.; Bodenhausen, G.; Wokaun, A. Principles of Nuclear Magnetic Resonance in One and Two Dimensions; Clarendon Press: Oxford, UK 1987.

(12) Neuhaus, D.; Williamson, M. The Nuclear Overhauser Effect in Structural and Conformational Analysis; VCH Publisher: New York, NY, 1989.

(13) Yip, P. F. J. Magn. Reson. 1990, 90, 382-383.

(14) For convenience, we consider only the magnitude of the cross relaxation rate in 2D experiments; for HRP-CN, all $\sigma$ are negative. 


$$
\left|\sigma_{i j}\right|=0.1 \gamma^{4} \hbar^{2} r_{i j}^{-6} \tau_{\mathrm{c}}
$$

At very short $\tau_{\mathrm{m}} \ll(2 \mathrm{D})^{-1},(R-D)^{-1}$, the expression in (1) is simplified to: ${ }^{12,13}$

$$
a_{i j \tau_{\mathrm{m} \rightarrow 0}}=\left(\frac{n_{i} n_{j}}{n_{i}+n_{j}}\right) \mathrm{v}_{0}\left|\sigma_{i j}\right| \tau_{\mathrm{m}}
$$

This initial linear slope of the NOESY cross peak buildup is the only quantitative method for extracting distances.

There exist numerous metalloproteins which exist solely in paramagnetic functional states that exhibit reasonably well resolved ${ }^{1} \mathrm{H}$ NMR spectra ${ }^{15-17}$ and for which the determination of interproton distances near the active site will provide valuable information on the detailed stereochemistry of functional residues. A particular class of these proteins are the heme peroxidases that exist in a high-spin ferric resting state which is readily inhibited by cyanide ligation to yield a low-spin ferric derivative. These proteins oxidize a variety of substrates at the expense of hydrogen peroxide and appear to rely on highly conserved distal catalytic residues to allow the facile formation of the activated complexes called compounds I and II..$^{18-20}$ The enzymes are large by 2D NMR standards, 34-150 $\mathrm{kDa}$, and detailed crystal structures for only one member, cytochrome $c$ peroxidase $(\mathrm{C} c \mathrm{P})$ have been reported.21,22 Numerous 1D and 2D ${ }^{1} \mathrm{H}$ NMR NOE studies on the hyperfine shifted resonances of cyanide complexes of $34-\mathrm{kDa} C c \mathrm{P},{ }^{23,24} \sim 44-\mathrm{kDa}$ horseradish peroxidase $4.5,25,26$ (HRP), $42-\mathrm{kDa}$ lignin peroxidase, ${ }^{27,28}$ 46-kDa manganese peroxidase, ${ }^{29} 78-\mathrm{kDa}$ lactoperoxidase, ${ }^{30}$ and $155-\mathrm{kDa}$ myeloperoxidase ${ }^{31}$ have been carried out. Successful ${ }^{1}$ H NMR studies have also been extended to genetically engineered variants of $C c P$ and HRP. ${ }^{32-34}$ The varied proteins reflect a remarkably conserved electronic structure that results in similar nonselective $T_{1} \mathrm{~S}$ of 3-140 ms for coordinated heme $\alpha$-substituents and histidine protons. However, while these enhanced relaxation rates for active site residues suggest that the decay of NOESY cross peaks will be rapid, the relatively large size of the proteins also guarantees reasonably rapid cross peak rise curves. ${ }^{3}$ Hence a heme peroxidase constitutes a test case for the realistic prospects for extracting distances from NOESY data for active site residues of a class of

(15) La Mar, G. N., Horrocks, W. D., Jr., Holm, R. H., Eds. NMR of Paramagnetic Molecules; Academic Press: New York, 1973.

(16) Satterlee, J. D. Annu. Rep. NMR Spectrosc. 1986, 17, 79-178.

(17) Bertini, I.; Luchinat, C. NMR of Paramagnetic Molecules in Biological Systems; Benjamin/Cummings: Menlo Park, CA, 1986

(18) Dunford, H. B.; Stillman, J.S. Coord. Chem. Rev. 1976, 19, 187-251.

(19) Dunford, H. B. In Peroxidases in Chemistry and Biology; Everse, J.,

Everse, K. E., Grisham, M. B., Eds.; CRC Press: Boca Raton, FL, 1991; Vol.

2, pp 1-23.

(20) Welinder, K. G. In Plant Peroxidases 1980-1990: Progress and Prospects in Biochemistry and Physiology; Gaspar, T., Penel, C., Greppin,

$\mathrm{H}$., Eds.; in press.

(21) Poulos, T. L.; Kraut, J. J. Biol. Chem. 1980, 255, 8199-8205.

(22) Finzel, B. C.; Poulos, T. L.; Kraut, J. J. Biol. Chem. 1984, 259, $13027-$ 13036.

(23) Satterlee, J. D.; Erman, J. E. Biochemistry 1991, 30, 4398-4405.

(24) Satterlee, J. D.; Russell, D. J.; Erman, J. E. Biochemistry 1991, 30, 9072-9077.

(25) Thanabal, V.; de Ropp, J. S.; La Mar, G. N. J. Am. Chem. Soc. 1988 $110,3027-3035$.

(26) de Ropp, J. S.; Yu, L. P.; La Mar, G. N. J. Biomol. NMR 1991, 1 $175-190$

(27) de Ropp, J. S.; La Mar, G. N.; Wariishi, H.; Gold, M. H. J. Biol Chem. 1991, 266, 5001-5008.

(28) Banci, L.; Bertini, I.; Turano, P.; Tien, M.; Kirk, T. K. Proc. Natl. Acad. Sci. U.S.A. 1991, 88, 6956-6960.

(29) Banci, L.; Bertini, I.; Pease, E. A.; Tien, M.; Turano, P. Biochemistry 1992, 31, 10009-10017.

(30) Thanabal, V.; La Mar, G. N. Biochemistry 1989, 28, 7038-7044. (31) Dugad, L. B.; La Mar, G. N.; Lee, H. C.; Ikeda-Saito, M.; Booth, K S.; Caughey, W. S. J. Biol. Chem. 1990, 265, 7173-7179.

(32) Satterlee, J. D.; Erman, J. E.; Mauro, J. M.; Kraut, J. Biochemistry 1990, 29, 8797-8804.

(33) Banci, L.; Bertini, I.; C., Turano, P.; Ferrer, J. C.; Mauk, A. G. Inorg. Chem. 1991, 39, 4510-4516.

(34) Veitch, N. C.; Williams, R. J. P.; Bray, R. C.; Burke, J. F.; Sanders, S. A.; Thorneley, R. N. F.; Smith, A. T. Eur. J. Biochem. 1992, 207, 521-531.

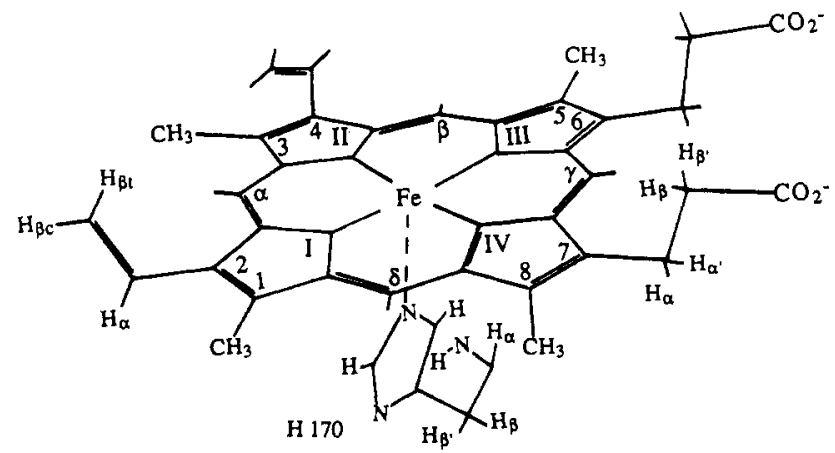

Figure 1. Structure and labeling scheme of the heme and axial His 170 as described in the crystal structure of $\mathrm{CcP} .21,22$ The vinyl orientations indicated are those determined for HRP-CN. 4,48

paramagnetic proteins for which success should also allow much more quantitative structural comparison among genetic variants and/or point mutants.

Our reference protein selected for this study is the cyanide complex of horseradish peroxidase isozyme C (HRP-CN), a 308 amino acid glycoprotein with a $\sim 23 \%$ carbohydrate content. ${ }^{18-20}$ In the absence of a crystal structure, ${ }^{1} \mathrm{H}$ NMR has served as the major tool for delineating the active site structure. ${ }^{4,5,25,26,34,35}$ The properties that make HRP-CN the ideal candidate for our study are that all of the resonances for the two bound endogenous ligands, the heme and axial His 170 (Figure 1), have been unambiguously identified, 4,5.26,34 the protein is remarkably stable, and HRP-CN is available in large quantities. Hence the functionality of many groups in HRP-CN, including some of the interproton distances, are already known and serve as a test for our measured values. The heme and axial His resonances, moreover, provide some of the broadest and most rapidly relaxed protons in the protein and therefore serve as the most serious test for obtaining distances.

2D NOESY studies of paramagnetic metalloproteins have infrequently utilized more than one mixing time, ${ }^{3}$ and those mixing times were generally selected on the basis of the nonselective $T_{1}$ of resonances of interest since the maximum cross peak intensity occurs for $\tau_{\mathrm{m}} \sim$ spin lattice relaxation time. ${ }^{11,12}$ In only a few cases have more than one $\tau_{\mathrm{m}}$ been used, and no detailed rise curve has been reported. As an extension of our investigation of the prospects for deriving distances from such rise curves, we also explore the basis for selecting the mixing time for a single or a limited series of NOESY spectra designed to optimize intensity of selected cross peaks. The particular questions we seek to answer in this study are the following. (1) Can cross peak rise curves for a significant number of dipolar contacts for a paramagnetically relaxed proton be quantitated? (2) How serious are secondary NOEs and spin diffusion for mixing times commonly used $(20$ $50 \mathrm{~ms}$ ) to collect NOESY maps for low-spin ferric heme peroxidases? (3) For primary NOEs, is it practical to quantitatively measure cross peak intensity for the short mixing times over which the rise curves are linear? (4) Do the linear portions of rise curves yield relative cross relaxation rates and distances consistent with known geometry? (5) Can absolute distances be obtained? (6) Which practically measurable relaxation property serves as the best basis for selecting mixing times for optimal cross peak sensitivity? And lastly, (7) does the geometric information on the heme and axial ligand provide an interpretation for HRP-CN on the basis of the crystal coordinates ${ }^{21,22}$ for $\mathrm{C} c \mathrm{P}-$ CN?

\section{Experimental Section}

Sample Preparation. Horseradish peroxidase (HRP) was purchased from Boehringer-Mannheim as a lyophilized salt-free powder; the protein is $98 \%$ isozyme $C$ with an $R Z$ (Reinheitszahl, $A_{403} / A_{280}$ ) value of 3.1 .

(35) de Ropp, J. S.; La Mar, G. N.; Smith, K. M.; Langry, K. C. J. Am. Chem. Soc. 1984, 106, 4438-4444. 


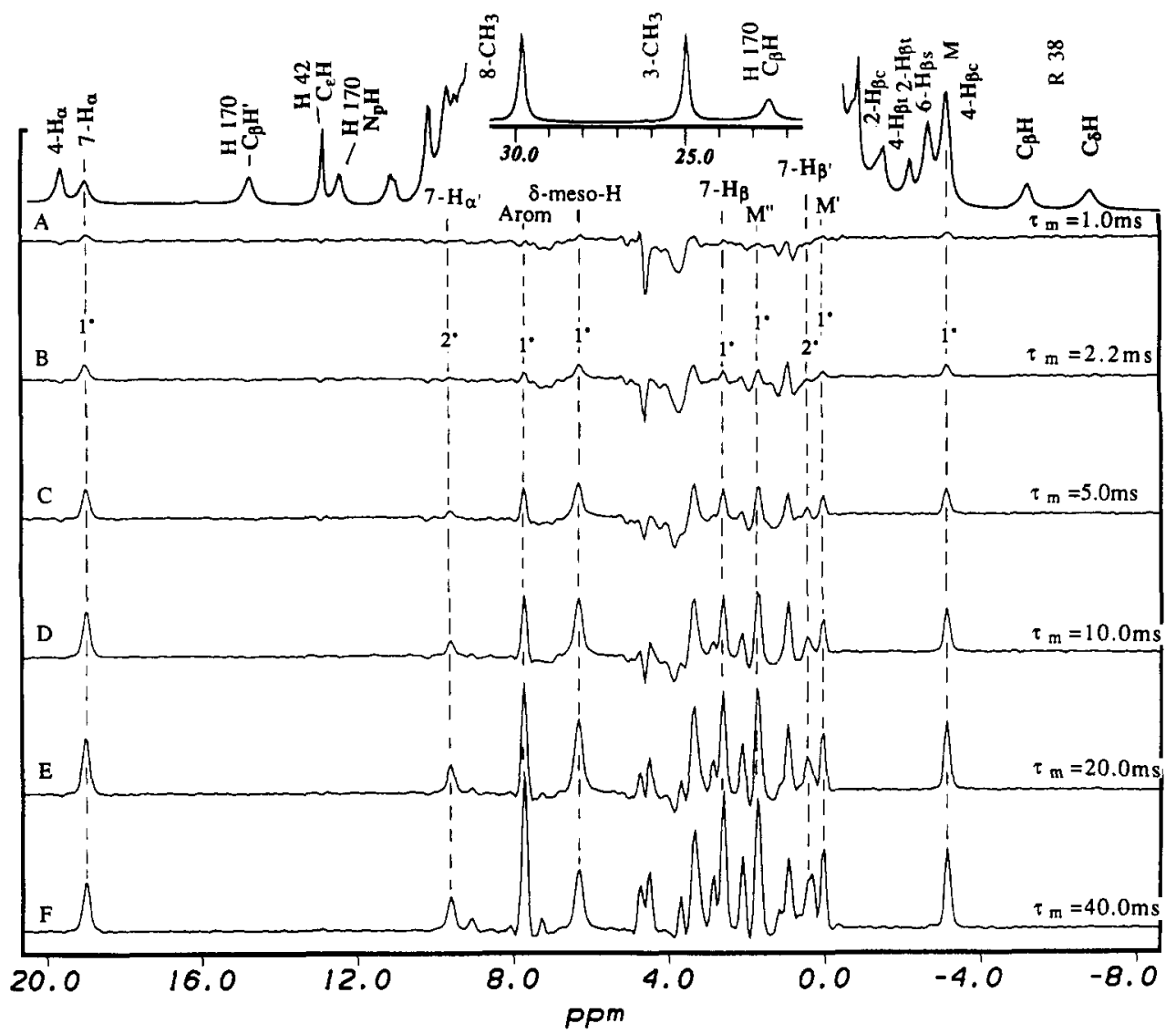

Figure 2. Slices through the 8- $\mathrm{CH}_{3}$ diagonal parallel to the $f_{2}$ axis for $\mathrm{HRP}-\mathrm{CN}$ in ${ }^{2} \mathrm{H}_{2} \mathrm{O}$ at $35^{\circ} \mathrm{C}, \mathrm{pH} 7.0$ as a function of mixing time: (A) $1.0 \mathrm{~ms}$, (B) $2.2 \mathrm{~ms}$, (C) $5.0 \mathrm{~ms}$, (D) $10 \mathrm{~ms}$, (E) $20 \mathrm{~ms}$, and (F) $40 \mathrm{~ms}$. The identical vertical scaling is used for all slices. The cross peaks of interest are labeled by their identity if known; otherwise the symbols $1^{\circ}, 2^{\circ}$ are used simply to designate whether the rise curve has its intercept at $\tau_{\mathrm{m}}=0$ (primary NOE) or at $\tau_{\mathrm{m}}>0$ (secondary NOE). Note the excellent sensitivity for cross peaks to weakly coupled protons even at 1.0 ms. Particularly noteworthy is the clearly primary NOE to $7 \mathrm{H}_{\alpha}$ but secondary NOE to $7 \mathrm{H}_{\alpha}{ }^{\prime}$. The cross peaks to resonances labeled Arom and $M, M^{\prime}, M^{\prime \prime}$ are to residues previously proposed ${ }^{3,26}$ as Phe and Ile, respectively.

Protein samples were prepared to be $3 \mathrm{mM}$ in $99.9 \%{ }^{2} \mathrm{H}_{2} \mathrm{O}$. A solution of potassium cyanide (Mallinckrodt) prepared in the same solvent was added to generate HRP-CN. The solution $\mathrm{pH}$ was adjusted to 6.8 with dilute ${ }^{2} \mathrm{HCl}$ or $\mathrm{NaO}^{2} \mathrm{H}$; the $\mathrm{pH}$ value was not corrected for the isotope effect. The majority of previous $2 D$ and $1 D$ NOE data $4,5,25,26$ on HRP$\mathrm{CN}$ have been collected at temperatures well above $40^{\circ} \mathrm{C}$ because of the much narrower lines and superior spectral resolution. However, since few other heme peroxidases exhibit the remarkable thermal stability of HRP, the present exploration of 2D NMR methods on HRP-CN is restricted to a more representative temperature, i.e., $35^{\circ} \mathrm{C}$, such that the results from the study can be extrapolated to other systems.

NMR Data Collection. Data were obtained on a GE-NMR $\Omega-500$ spectrometer operating at $11.75 \mathrm{~T}\left(500 \mathrm{MHz}\right.$ for $\left.{ }^{1} \mathrm{H}\right)$. NOESY data were collected in a $10-\mathrm{mm}^{1} \mathrm{H}$ probe from Cryomagnet Systems, Inc.; the $T_{1}$ data were collected in a $5-m m$ GE-NMR ${ }^{1} \mathrm{H}$ probe. All NOESY data sets ${ }^{10,36}$ were obtained under identical conditions: 352 scans were collected in 512 blocks ( $t_{1}$ acquisition time $8 \mathrm{~ms}$ ) using the hypercomplex method with a repetition rate of 5 scans/s for a total acquisition time of $10 \mathrm{~h}$. The recycle time was minimized to allow the maximum number of scans per unit time to optimize sensitivity. ${ }^{3}$ The value of $200 \mathrm{~ms}$ is consistent with the convention of using a recycle time of the order $1.5 T_{1}$, since the longest $T_{1} \mathrm{~s}$ for the heme $\alpha$-substituents and axial His resonances are known to be $<140 \mathrm{~ms}$. $^{5,26}$ A total of 1024 complex points in $t_{2}$ were collected over a $31.25-\mathrm{kHz}$ bandwidth for a $33-\mathrm{ms}$ acquisition time in $t_{2}$. The residual solvent line was presaturated with a low-power transmitter pulse. The basic NOESY sequence was utilized without any composite pulses in order to maximize the bandwidth of excitation. ${ }^{3}$ To maintain a constant pulse recycle time, the predelay was varied to compensate for any changes in the mixing time.

Nonselective $T_{1},\left(\rho^{\text {msel }}\right)^{-1}$, data were obtained by the basic $180^{\circ}-\tau-90^{\circ}$ pulse sequence using 8192 complex points over a $31.25-\mathrm{kHz}$ bandwidth. Selective $T_{1} \mathrm{~s},\left(\rho^{\mathrm{n} e \mathrm{l}}\right)^{-1}$, were obtained by the saturation recovery method,

(36) States, D. J.; Haberkorn, R. A.; Ruben, D. J. J. Magn. Reson. 1982, $48,286-292$. utilizing a low-power 30-ms selective saturation of the resonance of interest by the decoupler. The nonselective, $\rho^{\text {nsel }}$, and selective, $\rho^{\text {sel }}$, relaxation rates were obtained from the initial slope ${ }^{37}$ of the semilogarithmic plot of the fractional deviation of the $z$-magnetization from equilibrium versus the relaxation delay time 7 . Steady-state NOE measurements were made by saturating the resonance of interest with a $100-\mathrm{ms}$ selective decoupler pulse. Data were acquired by interleaving a block of scans with saturation on-resonance with an equal block of scans off-resonance. Difference spectra and reference spectra were plotted to the same scale and the NOE determined from: ${ }^{12}$

$$
\eta_{i}\{j\}=\frac{I-I_{0}}{J_{0}}=\frac{\sigma_{i j}}{\rho_{i}}
$$

where $j$ is the resonance saturated, with intensity $J_{0}$ prior to saturation, which yields an NOE to peak $i$, with intensity $I$ and $I_{0}$ with and without complete saturation of $j$.

NMR Data Processing. Raw 2D data sets were transferred to an IRIS 4D/35 and processed using the Hare Research software package Felix (version 1.1). $45^{\circ}$-shifted sine-bell-squared apodization was applied in $t_{2}$ over 1024 points, and $30^{\circ}$-shifted sine-bell-squared apodization was employed in $t_{1}$ over 256 points. The $t_{2}$ data were phase-corrected and base line straightened, and the $t_{1}$ data were zero-filled twice (for a final data matrix of $1024 \times 1024$ points) and, after Fourier transformation, phase-corrected with a small zero-order phase correction. Cross peak heights for rise curves (Figures 3-6) were obtained by plotting $f_{2}$ slices through the diagonal peak of interest and measuring cross peak heights in centimeters. All slices were plotted at the same arbitrary but uniform scale; uncertainties in cross peak heights are \pm 0.1 units. Cross peak intensities between methyls and single protons were scaled by dividing ${ }^{13}$ by 3 . Cross peak and diagonal peak volumes were obtained using the appropriate Felix subroutine. $R_{l}$ values, the selective $T_{1}^{-1}$ by diagonal

(37) Granot, J. J. Magn. Reson. 1982, 49, 257-270. 


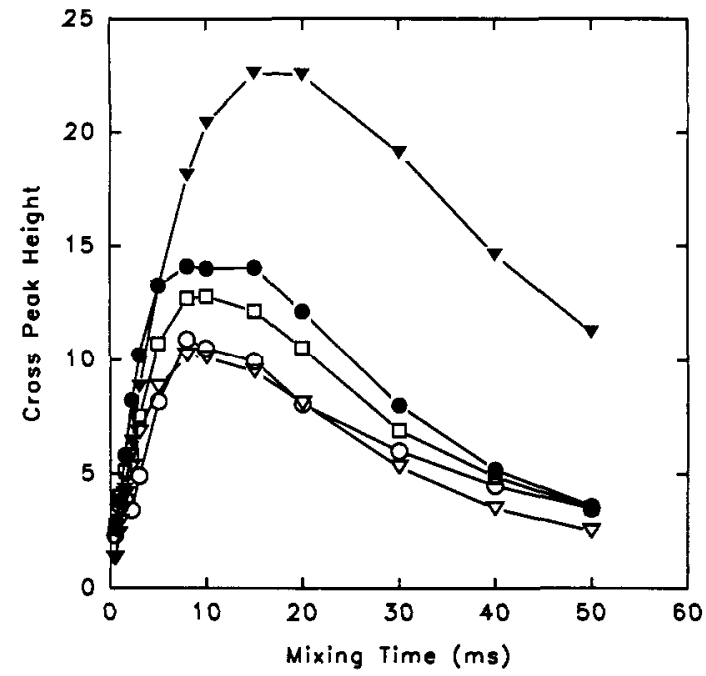

Figure 3. NOESY cross peak intensity versus mixing time, $\tau_{\mathrm{m}}$, for strongly coupled (geminal) proton pairs $7 \mathrm{H}_{\alpha} \rightarrow 7 \mathrm{H}_{\alpha}^{\prime}(\nabla), 4 \mathrm{H}_{\beta c} \rightarrow 4 \mathrm{H}_{\beta t}(\nabla)$, His $170 \mathrm{C}_{\beta} \mathrm{H} \rightarrow \mathrm{C}_{\beta} \mathrm{H}^{\prime}(\square)$, Arg $38 \mathrm{C}_{\beta} \mathrm{H} \rightarrow \mathrm{C}_{\beta} \mathrm{H}^{\prime}(\bullet)$, and Arg $38 \mathrm{C}_{\delta} \mathrm{H} \rightarrow \mathrm{C}_{\delta} \mathrm{H}^{\prime}$ $(0)$. The vertical scaling is identical for all data. The data are for the $f_{2}$ slices through the diagonal of the better resolved proton of the pair.

decay, ${ }^{10,38}$ were determined from the slope of the plots of diagonal peak volume vs mixing time. The cross relaxation rate was determined by rearranging eq 3 to eq 5 and using the cross peak volume at the largest $\tau_{m}$ value for which the cross peak rise curve was judged strictly linear; this $\tau_{\mathrm{m}}$ value is designated $\tau_{\mathrm{m}}{ }^{*}$.

$$
\left|\sigma_{i j}\right|=\frac{a_{i j}\left(\tau_{\mathrm{m}}^{*}\right)}{q\left(V_{0 i} / n_{i}\right) \tau_{\mathrm{m}}{ }^{*}}
$$

where $q=1$ for a pair of protons and $q=3$ for a proton interacting with a methyl group; $V_{0 i}$ is the diagonal volume at $\tau_{\mathrm{m}}=0$ for peak $i$. For geminal protons, $\tau_{\mathrm{m}}{ }^{*}$ values as short as $1.5 \mathrm{~ms}$ were used, while for more weakly coupled proton pairs, $\tau_{\mathrm{m}}$ "values up to $3 \mathrm{~ms}$ were used. The use of $\tau_{\mathrm{m}}{ }^{*}$ rather than a linear fit of $a_{i j}$ values is dictated by the fractionally larger uncertainties of $a_{i j}$ for $\tau_{\mathrm{m}}<\tau_{\mathrm{m}} *$.

\section{Results}

Rise Curves. Representative $f_{2}$ slices of the NOESY map are illustrated in Figure 2 for the $8-\mathrm{CH}_{3}$ diagonal for mixing times of $1,2.2,5,10,20$, and $40 \mathrm{~ms}$; the reference trace for HRP-CN is shown along the top of Figure 2 . The excellent sensitivity achieved is apparent by the clear detection of several cross peaks to weakly coupled protons with resolved signals even for $\tau_{\mathrm{m}}=1$ $\mathrm{ms}$. Several of the signals of interest in this report are labeled by their known assignments, $4,5,26$ and the symbols $1^{\circ}$ and $2^{\circ}$ are given to designate whether the signal appears to rise monotonically from $\tau_{m}=0$ (primary NOEs) or develops only after some delay at $\tau_{\mathrm{m}}>0$ (secondary NOEs). The great wealth of information in this figure is made obvious by the detection of over a dozen cross peaks for the heme methyl, of which the majority, but not all, appear to be primary. Peaks in the unresolved $10-0 \mathrm{ppm}$ region are of no interest in this report unless they are known to arise ${ }^{4,26}$ from the heme or axial His 170 . Essentially all the significant primary NOEs for these weakly coupled protons are identified and can be quantitated for $\tau_{\mathrm{m}}$ as short as $3 \mathrm{~ms}$. Moreover, clearly secondary NOEs that develop only in the 3-5 ms window, such as those marked $7 \mathrm{H}_{\alpha}{ }^{\prime}$ and $7 \mathrm{H}_{\beta}{ }^{\prime}$ in Figure 2, can be identified (see below). However, while it is obvious that there is sufficient sensitivity to detect and quantify cross peak intensity at short mixing times, it is also clear from Figure 2 that there are limitations to identifying and quantifying cross peak intensity at short mixing times in the window of the intense diamagnetic

(38) Mirau, P. A.; Bovey, F. A. J. Am. Chem. Soc. 1986, 108, 5130-5134. envelope, $0-8 \mathrm{ppm}$, where $t_{1}$ ridges $^{39}$ and other artifacts tend to obscure the cross peaks when they are weak (i.e., $\tau_{\mathrm{m}} \leq 2.2 \mathrm{~ms}$ ). At large $\tau_{m}$, the artifacts make only minor contributions to the slices. Nevertheless, it is apparent that cross peak intensity is more difficult to quantify for peaks in the diamagnetic window than for resolved resonances (see below).

More impressive is the detectability of cross peaks involving strongly dipolar coupled proton pairs such as geminal methylene groups, for which the cross peak intensity at $\tau_{\mathrm{m}}=0.5 \mathrm{~ms}$ (not shown) exceeds that for most of the resolved peaks at $\tau_{\mathrm{m}}=5.0$ $\mathrm{ms}$ for the weakly coupled protons in Figure 2. The intensity profiles (in arbitrary units, but the same units for all graphs in this report) as a function of $\tau_{\mathrm{m}}$ for cross peaks for expected geminal proton pairs, the propionate $7-\mathrm{H}_{\alpha} \mathrm{s}$, 4-vinyl $\mathrm{H}_{\beta} \mathrm{s}$, axial His 170 $\mathrm{C}_{\beta} \mathrm{Hs}$, and $\mathrm{Arg} 38 \mathrm{C}_{\beta} \mathrm{Hs}$ and $\mathrm{C}_{\delta} \mathrm{Hs}$, are illustrated in Figure 3. The cross peaks are designated $i \rightarrow j$ when the slice in the $f_{2}$ dimension through the diagonal of peak $i$ is analyzed. Essentially the same rise curves are obtained for the cross peak symmetric about the diagonal (not shown). The curve for the unresolved propionate $7 \mathrm{H}_{\beta}$ s does not yield useful points ${ }^{40}$ for $\tau_{\mathrm{m}} \leq 2.2 \mathrm{~ms}$, but the steep increase in intensity that characterizes a geminal proton pair, however, is readily recognized in spite of the absence of the data at short $\tau_{\mathrm{m}}$ (not shown). A noteworthy observation is that for most of the geminal proton pairs in Figure 3 the rise curves reach a maximum at $\tau_{\mathrm{m}} \sim 10 \mathrm{~ms}$, which is at a significantly shorter time than that expected from nonselective $T_{1}$ for any of the resonances of interest (see below). The maximum cross peak intensity at $\tau_{\mathrm{m}} \sim 20 \mathrm{~ms}$ for the $4 \mathrm{H}_{\beta} \mathrm{s}$ is similarly at a much shorter time than the nonselective $T_{1} \mathrm{~s}$. Nonselective $T_{1} \mathrm{~s}$ at 50 and 55 ${ }^{\circ} \mathrm{C}$ have been previously reported; ${ }^{5,26}$ the presently determined values for the resolved resonances at $35^{\circ} \mathrm{C}$ are listed in Table I. The consequence of the cross peak maxima occurring at such short $\tau_{\mathrm{m}}$ is that the rise curves for geminal protons in the active site are strictly linear to $\tau_{\mathrm{m}}$ only $\sim 1.5 \mathrm{~ms}$.

The remaining cross peak intensity profiles with $\tau_{\mathrm{m}}$ are considered in terms of the substituents on and flanking each of the pyrroles that yield resolved resonances, as given in Figures 4 and 5, and for the axial His 170 (Figure 1), as shown in Figure 6. All rise curves represent monotonic increases to a maximum, and then monotonic decreases, except for those involving vicinal protons for the vinyl groups (see below). Figure 4A presents the rise curves for pyrrole II with the resolved $3-\mathrm{CH}_{3}$ and 4-vinyl signals. Within the vinyl group, the $4 \mathrm{H}_{\beta c} \rightarrow 4 \mathrm{H}_{\beta r}$ geminal rise curve has been considered above. The $4 \mathrm{H}_{\alpha} \rightarrow 4 \mathrm{H}_{\beta c}$ and $4 \mathrm{H}_{\alpha} \rightarrow 4 \mathrm{H}_{\mathrm{At}}$ rise curves exhibit a behavior different from that of other resonances considered; the intensity at short $\tau_{\mathrm{m}}$ oscillates with $\tau_{\mathrm{m}}$ (Figure 4A). A similar behavior is observed for $2 \mathrm{H}_{\alpha} \rightarrow 2 \mathrm{H}_{B c}$ and $2 \mathrm{H}_{\alpha} \rightarrow 2 \mathrm{H}_{\beta t}$ (not shown). This oscillatory behavior is due to zeroquantum coherence via the scalar interaction and reflects the fact that these proton pairs have strong scalar coupling relative to their dipolar coupling. ${ }^{10,11}$ Such oscillations have been characterized in diamagnetic proteins for proton pairs which show strong scalar and weak dipolar coupling. ${ }^{41}$ This is the first case for the detection of such oscillations in a paramagnetic compound. This oscillation precludes the detection of the initial linear proton of the rise curve. The $4 \mathrm{H}_{\alpha} \rightarrow 4 \mathrm{H}_{\beta t}$ rise curve should reflect a secondary NOE even with the oscillation; the observed curve is consistent with this expectation. This scalar modulation can be

(39) Mehlkopf, A. F.; Korbee, D.; Tiggelman, T. A.; Freeman, R. J. Magn. Reson. 1984, 58, 315-323. Turner, C. J.; Patt, S. L. J. Magn. Reson. 1989, 85, 492-505. Derome, A. E.; Williamson, M. P. J. Magn. Reson. 1990, 88, $177-185$.

(40) Cross peaks to the diamagnetic region frequently suffered from distorted intensities due to $t_{1}$ ridges and other artifacts. Cross peaks $a_{i j}$, where resonance $i$ was in the diamagnetic region and resonance $j$ shifted outside, were quantified by using the $a_{i j}$ volume at the $f_{1}$ frequency of $i$, placing the cross peak outside the region of most artifacts.

(41) Kumar, A.; Wagner, G.; Ernst, R. R.; Wüthrich, K. J. Am. Chem. Soc. 1981, 103, 3654-3658. 

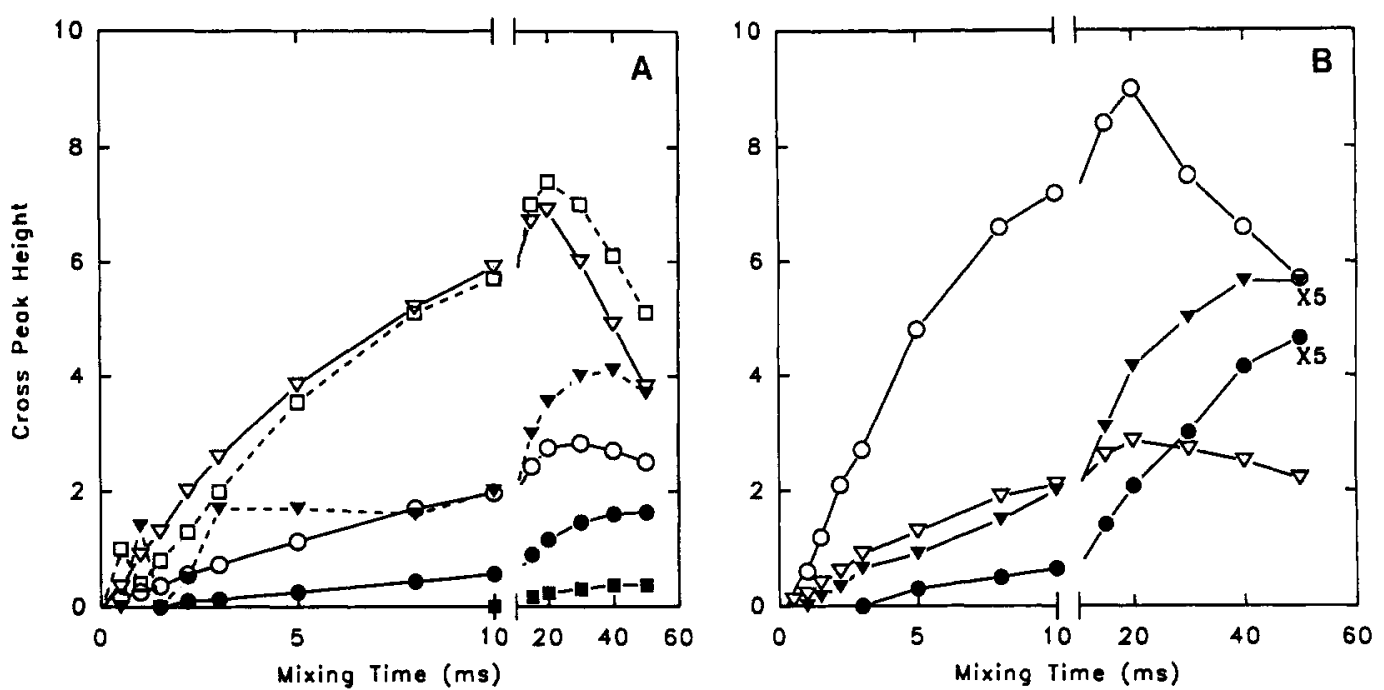

Figure 4. NOESY cross peak buildup curves as a function of mixing time, $\tau_{\mathrm{m}}$, for resonances of pyrroles I and II of the heme of $\mathrm{HRP}-\mathrm{CN}$ in ${ }^{2} \mathrm{H}_{2} \mathrm{O}$ at $35^{\circ} \mathrm{C}, \mathrm{pH} 7.0$. The $f_{2}$ slices were used in each case, and the slice is identified by the convention: diagonal $\rightarrow$ cross peak; the same scaling is used, but peaks involving methyls ${ }^{13}$ are divided by 3 . Panel $A$ presents data for pyrrole II: $3-\mathrm{CH}_{3} \rightarrow 4 \mathrm{H}_{\beta t}(0), 3 \mathrm{CH}_{3} \rightarrow 4 \mathrm{H}_{\beta c}(\bullet), 4 \mathrm{H}_{\alpha} \rightarrow 3 \mathrm{CH}_{3}(\mathbf{0}), 4 \mathrm{H}_{\alpha} \rightarrow 4 \mathrm{H}_{\beta c}$ $(\square), 4 \mathrm{H}_{\alpha} \rightarrow 4 \mathrm{H}_{\beta t}(\nabla)$, and $\beta$-meso- $\mathrm{H} \rightarrow 4 \mathrm{H}_{\alpha}(\nabla)$. Note the oscillation of the intensity (shown by dashed lines) for $4 \mathrm{H}_{\alpha} \rightarrow 4 \mathrm{H}_{\beta c}$ and $4 \mathrm{H}_{\alpha} \rightarrow 4 \mathrm{H}_{\beta \mathrm{r}}$ at short mixing times which results from zero-quantum coherence. ${ }^{10,41}$ Note that both the $4 \mathrm{H}_{\alpha} \rightarrow 3 \mathrm{CH}_{3}(\square)$ and $3 \mathrm{CH}_{3} \rightarrow 4 \mathrm{H}_{\beta c}(\bullet)$ NOEs are secondary. Panel B presents data for the pyrrole I/II junction: $3 \mathrm{CH}_{3} \rightarrow 2 \mathrm{H}_{\beta \mathrm{t}}(\nabla), 3 \mathrm{CH}_{3} \rightarrow 2 \mathrm{H}_{\beta c}(\bullet)$ (both with vertical expansion $\times 5$ compared to other plots), $\alpha$-meso$\mathrm{H} \rightarrow 3 \mathrm{CH}_{3}(\nabla)$, and $\alpha-$ meso-H $\rightarrow 2 \mathrm{H}_{\theta t}(0)$. Primary NOEs are designated by open markers and secondary NOEs by closed markers.
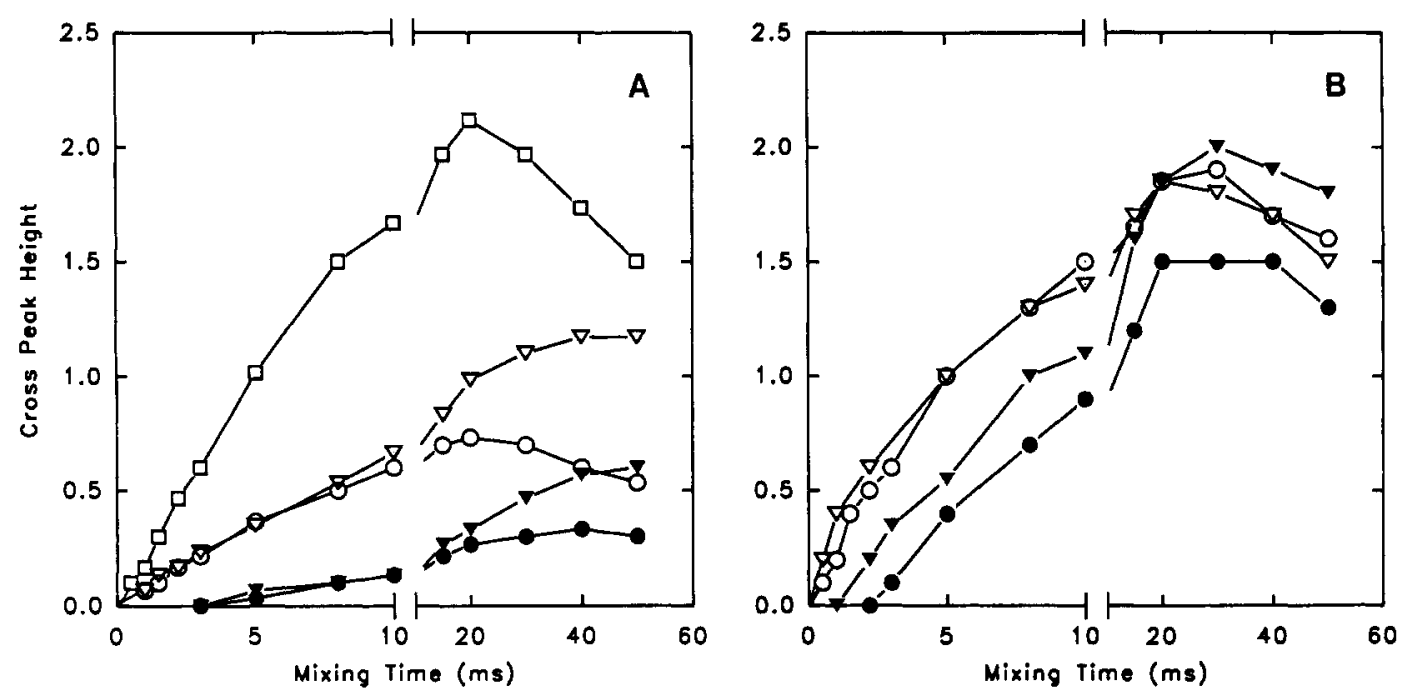

Figure 5. NOESY cross peak intensity (in arbitrary units) as a function of mixing time, $\tau_{\mathrm{m}}$, for pyrrole IV of $\mathrm{HRP}-\mathrm{CN}$ in ${ }^{2} \mathrm{H}_{2} \mathrm{O}$ at $35{ }^{\circ} \mathrm{C}$, pH 7.0 . Panel A, cross peaks involving the $8 \mathrm{CH}_{3}$ group: $\delta$-meso- $\mathrm{H} \rightarrow 8 \mathrm{CH}_{3}(\square), 7 \mathrm{H}_{\alpha} \rightarrow 8 \mathrm{CH}_{3}(0), 7 \mathrm{H}_{\alpha}^{\prime} \rightarrow 8 \mathrm{CH}_{3}(\bullet), 7 \mathrm{H}_{\beta} \rightarrow 8 \mathrm{CH}_{3}(\nabla)$, and $7 \mathrm{H}_{\beta}^{\prime} \rightarrow 8 \mathrm{CH}_{3}(\nabla)$. Panel B, vicinal cross peaks within the 7-propionate group: $7 \mathrm{H}_{\beta} \rightarrow 7 \mathrm{H}_{\alpha}(0), 7 \mathrm{H}_{\beta} \rightarrow 7 \mathrm{H}_{\alpha}^{\prime}(\bullet), 7 \mathrm{H}_{\beta}^{\prime} \rightarrow 7 \mathrm{H}_{\alpha}(\nabla)$, and $7 \mathrm{H}_{\beta}^{\prime} \rightarrow 7 \mathrm{H}_{\alpha}^{\prime}(\nabla)$. Note that in both panels the open markers reflect primary NOEs while the closed markers show secondary NOEs.

removed by varying the mixing time randomly by a small increment; ${ }^{10}$ such experiments, however, were not attempted on this system.

The $3-\mathrm{CH}_{3} \rightarrow 4 \mathrm{H}_{\beta \mathrm{t}}$ and $\beta$-meso- $\mathrm{H} \rightarrow 4 \mathrm{H}_{\alpha}$ rise curves in Figure $4 \mathrm{~A}$ reflect primary NOEs with a significant linear portion (to $\tau_{\mathrm{m}}$ $=3 \mathrm{~ms}$ ). While $4 \mathrm{H}_{\alpha} \rightarrow 3-\mathrm{CH}_{3}$ and $3-\mathrm{CH}_{3} \rightarrow 4 \mathrm{H}_{\beta c}$ cross peaks are observed at long $\tau_{\mathrm{m}}>5 \mathrm{~ms}$, the rise curves in Figure 4 clearly extrapolate to 0 for $\tau_{m}>0$, dictating that the NOEs are secondary. The $\alpha-$ meso- $\mathrm{H} \rightarrow 3-\mathrm{CH}_{3}$ rise curve shown in Figure 4B is primary, as expected, and yields a significant initial linear portion to $5 \mathrm{~ms}$. However, $3-\mathrm{CH}_{3}$ yields an intense cross peak not only to $\alpha$-meso-H but also to a proton which resonates very close to $\alpha$-meso- $\mathrm{H}^{4,5,26}$ (not shown). The fact that both rise curves involving meso-H reach maxima at shorter $\tau_{\mathrm{m}}(\sim 20 \mathrm{~ms})$ than those for the pyrrole substituents is likely due to the expected more rapid paramagnetic relaxation of meso-Hs. Previous $1 D$ NOE studies had reported 4 a dipolar contact between the $3-\mathrm{CH}_{3}$ and 2-vinyl $\mathrm{H}_{\beta} \mathrm{s}$. The rise curves for $3-\mathrm{CH}_{3} \rightarrow 2-\mathrm{H}_{\beta t}$ and $3-\mathrm{CH}_{3} \rightarrow 2-\mathrm{H}_{\beta c}$ in Figure 4B, however, suggest that these NOEs are secondary, since the intercepts are at $\tau_{\mathrm{m}} \sim 1$ and $3 \mathrm{~ms}$, respectively. This conclusion is supported by the observation of a much steeper rise curve for a primary NOE between $2 \mathrm{H}_{\theta t}$ and $\alpha$-meso- $\mathrm{H}$ and between $\alpha$-meso- $\mathrm{H}$ and $3-\mathrm{CH}_{3}$, indicating that the weak $3-\mathrm{CH}_{3} \rightarrow 2 \mathrm{H}_{\beta \mathrm{c}}$ cross peak at $\tau_{\mathrm{m}}>1 \mathrm{~ms}$ arises because of the indirect path $2 \mathrm{H}_{\mathrm{\rho t}}$ $\rightarrow \alpha$-meso- $\mathrm{H} \rightarrow 3-\mathrm{CH}_{3}$ (see Discussion).

The cross peak rise curves for the pyrrole IV resonances are given in Figure 5. The $\delta$-meso- $\mathrm{H} \rightarrow 8-\mathrm{CH}_{3}$ rise curve is primary, as expected, as is the rise curve for the $7 \mathrm{H}_{\alpha} \rightarrow 8-\mathrm{CH}_{3}$ (Figure 5A). In contrast, the rise curve $7 \mathrm{H}_{\alpha}{ }^{\prime} \rightarrow 8-\mathrm{CH}_{3}$ clearly reflects a secondary NOE; hence $8-\mathrm{CH}_{3}$ is closer to $7 \mathrm{H}_{\alpha}$ than $7 \mathrm{H}_{\alpha}{ }^{\prime}$. Similarly, the $7 \mathrm{H}_{\beta} \rightarrow 8-\mathrm{CH}_{3}$ rise curve reflects a primary NOE, while that for $7 \mathrm{H}_{\beta}{ }^{\prime} \rightarrow 8-\mathrm{CH}_{3}$ indicates a secondary NOE; hence $8-\mathrm{CH}_{3}$ is closer to $7 \mathrm{H}_{\beta}$ than $7 \mathrm{H}_{\beta}{ }^{\prime}$. The $7 \mathrm{H}_{\alpha} \mathrm{s}$ and $7 \mathrm{H}_{\beta} \mathrm{s}$ each yielded the expected steep rise curves for geminal protons $\left(7 \mathrm{H}_{\alpha}\right.$ shown in Figure 3). Further information on the propionate orientation can be gleaned from the propionate vicinal dipolar contacts shown in Figure 5B; primary NOEs are observed for the 


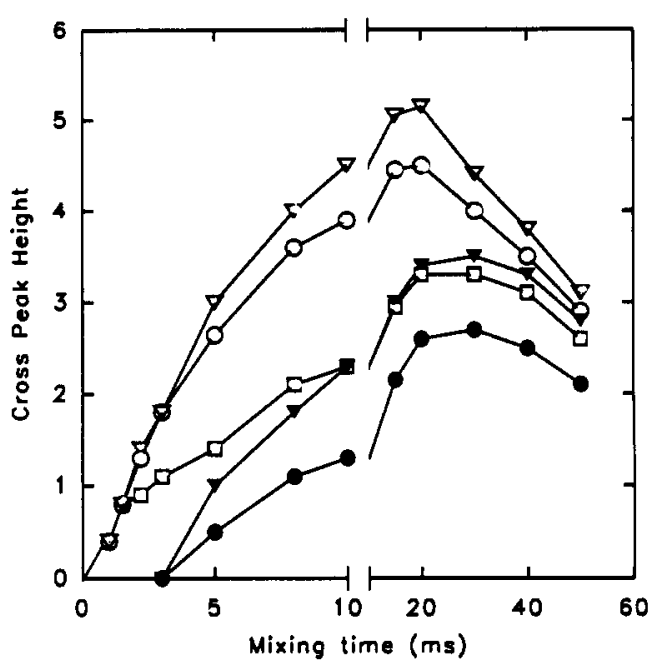

Figure 6. NOESY cross peak intensity (in arbitrary units) as a function of mixing time, $\tau_{\mathrm{m}}$, for vicinal protons of the axial His 170 of HRP-CN in ${ }^{2} \mathrm{H}_{2} \mathrm{O}$ at $35^{\circ} \mathrm{C}, \mathrm{pH} 7.0 ; \mathrm{C}_{\beta} \mathrm{H} \rightarrow \mathrm{C}_{\alpha} \mathrm{H}(0), \mathrm{C}_{\beta} \mathrm{H} \rightarrow \mathrm{NpH}(\bullet), \mathrm{C}_{\beta} \mathrm{H}^{\prime} \rightarrow \mathrm{C}_{\alpha} \mathrm{H}$ $(\nabla), \mathrm{C}_{\beta} \mathrm{H}^{\prime} \rightarrow \mathrm{NpH}(\nabla)$, and $\mathrm{C}_{\alpha} \mathrm{H} \rightarrow \mathrm{NpH}(\square)$. Note that open markers reflect primary NOEs while closed markers represent secondary NOEs.

Table I. ${ }^{1} \mathrm{H}$ NMR Spectral Parameters for HRP-CN ${ }^{a, b}$

\begin{tabular}{|c|c|c|c|c|c|c|c|}
\hline peak & shift ${ }^{c}$ & $\rho^{\text {neel } d}$ & $\rho^{\text {nel }}$ e & $R^{f}$ & $\Delta \rho \rho^{s}$ & $\Delta \rho_{i}^{\prime h}$ & $\rho^{\text {nel }} / \rho^{\text {nsel }}$ \\
\hline $\begin{array}{l}2-H_{B c} \\
2-H_{B t}\end{array}$ & $\begin{array}{l}-1.53 \\
-2.62\end{array}$ & $i$ & & & & & \\
\hline $3-\mathrm{CH}_{3}$ & 24.96 & 7.3 & 23 & 26 & 16 & 19 & 3.2 \\
\hline $4-\mathrm{H}_{\alpha}$ & 19.67 & 5.8 & 48 & 50 & 42 & 44 & 8.3 \\
\hline $4-H_{\beta c}$ & -3.09 & $i$ & & & & & \\
\hline $4-\mathrm{H}_{p t}$ & -2.14 & $i$ & & & & & \\
\hline $6-\mathrm{H}_{\beta}$ & -2.66 & $i$ & & & & & \\
\hline $\begin{array}{l}7-\mathrm{H}_{\alpha} \\
7-\mathrm{H}_{\alpha}^{\prime}\end{array}$ & $\begin{array}{r}19.03 \\
9.71\end{array}$ & $\begin{array}{l}6.4 \\
i\end{array}$ & 67 & 87 & 61 & 81 & 10 \\
\hline $\begin{array}{l}-\mathrm{H}_{\alpha} \\
8-\mathrm{CH}_{3}\end{array}$ & $\begin{array}{r}9.11 \\
29.78\end{array}$ & $\begin{array}{l}l \\
9.2\end{array}$ & 29 & 29 & 20 & 20 & 3.2 \\
\hline His $170 \mathrm{C}_{\beta} \mathrm{H}$ & 22.48 & 18 & 74 & 99 & 56 & 81 & 4.1 \\
\hline His $170 \mathrm{C}_{\beta} \mathrm{H}^{\prime}$ & 14.83 & 15 & 56 & 95 & 41 & 80 & 3.7 \\
\hline His $170 \mathrm{~N}_{\mathrm{p}} \mathrm{H}$ & 12.52 & 13 & 43 & 50 & 30 & 37 & 3.3 \\
\hline His $170 \mathrm{C}_{\alpha} \mathrm{H}$ & 9.86 & $i$ & & & & & \\
\hline $\mathrm{His} 42 \mathrm{C}_{6} \mathrm{H}$ & 12.97 & 6.3 & 13 & 16 & 7 & 10 & 2.1 \\
\hline $\operatorname{Arg} 38 \mathrm{C}_{\beta} \mathrm{H}$ & -5.23 & 9.8 & 69 & 107 & 59 & 97 & 7.0 \\
\hline Arg 38 & -6.82 & 30 & 90 & 94 & 60 & 64 & 3.0 \\
\hline
\end{tabular}

a $3 \mathrm{mM}$ HRP in ${ }^{2} \mathrm{H}_{2} \mathrm{O}$ at $35^{\circ} \mathrm{C}, \mathrm{pH} 7.0{ }^{b}$ The shifts at $35^{\circ} \mathrm{C}$ for nonresolved heme signals, in ppm, are $1-\mathrm{CH}_{3}, 2.68 ; 2-\mathrm{H}_{\alpha}, 5.08 ; \alpha$-meso$\mathrm{H}, 1.17 ; \beta$-meso-H, 6.93; 5 - $\mathrm{CH}_{3}, 6.45 ; \gamma$-meso- $\mathrm{H}, 4.78 ; 7 \mathrm{H}^{\prime}, 0.52 ; 7 \mathrm{H}_{\beta}$, $2.68 ; \delta$-meso-H, 6.44. ${ }^{c}$ Chemical shift, in ppm from DSS; uncertainty $\pm 0.01 \mathrm{ppm}{ }^{d}$ Nonselective relaxation rate, $\left(1 / T_{1}{ }^{\mathrm{neel}}\right)$, in $\mathrm{s}^{-1}$, obtained from the initial slope from a nonselective inversion-recovery experiment; uncertainty $\pm 10 \%$. - Selective relaxation rate, $\left(1 / T_{1}{ }^{\text {sel }}\right)$, in $\mathrm{s}^{-1}$, obtained from a selective saturation-recovery experiment; uncertainty $\pm 10 \%$. $f$ Decay constant, in $\mathrm{s}^{-1}$, for the diagonal intensity in NOESY spectra as a function of mixing time; uncertainty $10 \% .8 \Delta \rho_{l}=\rho_{l}^{\text {sel }}-\rho_{i}^{\text {nsel }} .{ }^{h} \Delta \rho_{i}^{\prime}$ $=R_{i}-\rho f^{\text {mel }}$. 'Insufficiently resolved at $35^{\circ} \mathrm{C}$ to obtain relaxation times.

pairs $7 \mathrm{H}_{\beta} \rightarrow 7 \mathrm{H}_{\alpha}$ and $7 \mathrm{H}_{\beta}{ }^{\prime} \rightarrow 7 \mathrm{H}_{\alpha}{ }^{\prime}$, while the pairs $7 \mathrm{H}_{\beta} \rightarrow 7 \mathrm{H}_{\alpha}$, $7 \mathrm{H}_{\beta} \rightarrow 7 \mathrm{H}_{\alpha}{ }^{\prime}$ exhibit secondary NOEs.

The cross peak rise curves for the vicinal protons of the axial His 170 resonances (excluding the imidazole ring, whose resonances are $\sim 400-\mathrm{Hz}$ broad and whose dipolar connectivities can be detected only by $1 D$ NOEs) ${ }^{5}$ are shown in Figure 6; the geminal $\mathrm{C}_{\beta} \mathrm{H} \rightarrow \mathrm{C}_{\beta} \mathrm{H}^{\prime}$ rise curve has been presented in Figure 3. The $\mathrm{C}_{\sigma-}$ Hs each give only one other primary NOE, $\mathrm{C}_{\beta} \mathrm{H} \rightarrow \mathrm{C}_{\alpha} \mathrm{H}$ and $\mathrm{C}_{\beta} \mathrm{H}^{\prime} \rightarrow \mathrm{N}_{\mathrm{P}} \mathrm{H}$, with the large $\mathrm{C}_{\beta} \mathrm{H} \rightarrow \mathrm{N}_{\mathrm{P}} \mathrm{H}$ and $\mathrm{C}_{\beta} \mathrm{H}^{\prime} \rightarrow \mathrm{C}_{\alpha} \mathrm{H}$ NOEs at long $\tau_{m}$ clearly secondary. The rise curve for $\mathrm{C}_{\alpha} \mathrm{H} \rightarrow \mathrm{N}_{\mathrm{p}} \mathrm{H}$ is harder to quantitate because both resonances are in or close to the intense diamagnetic envelope ${ }^{40}$ However, the intercept appears to occur at $\tau_{\mathrm{m}}=0$, and hence the large NOE is judged primary. Each of the primary NOEs yields initial linear portions for the rise curves only to $\sim 2.2 \mathrm{~ms}$ for distance estimation (see below).
Distance Determination. The determination of $\sigma_{i j}$ (eq 5) requires the diagonal volume at $\tau_{\mathrm{m}}=0, V_{0 i}$, and the cross peak volumes at a $\tau_{\mathrm{m}} \neq 0$ value which is clearly on the strictly linear portion of the rise curves in Figures 3-6. The normalized diagonal volumes of $\tau_{\mathrm{m}}=0, V_{0 i} / n_{i}$, (which must correlate with proton intensity in a nonsaturated trace) for the nine clearly resolved resonances for which this determination could be made yield a range 35.4-48.7 in arbitrary units, for a mean value $V_{0 i} / n_{i}=42.1$ \pm 6.7 , i.e., an uncertainty $\pm 15 \%$. This value was used in all subsequent calculations for the diagonal of both resolved and unresolved resonances. The volumes of the cross peaks, $a_{i j}\left(\tau_{\mathrm{m}}{ }^{*}\right)$, at the longest $\tau_{\mathrm{m}}$ for which the rise curve is strictly linear (at $\left.\tau_{\mathrm{m}}{ }^{*}\right)$, for resonaces of interest are listed in Table II, along with the $\tau_{\mathrm{m}}{ }^{*}$ values. The $a_{i j}\left(\tau_{\mathrm{m}}{ }^{*}\right)$ values for a proton pair are similarly judged reliable 42 to $\pm 15 \%$, which results in $\sigma_{i j}$ values with uncertainties $\pm 30 \%$ and $r_{i j}$ values reliable to $\pm 5 \%$. The first seven entries in Table II are for proton sets for which $\boldsymbol{r}_{i j}$ values are essentially independent of protein constraints and hence can be considered known. They serve as calibration for the ability to obtain distances. For geminal proton pairs, ${ }^{43}$ the maximum in the rise curve near $\tau_{\mathrm{m}} \sim 10 \mathrm{~ms}$ dictates $\tau_{\mathrm{m}}{ }^{*}$ values $\leq 1.5 \mathrm{~ms}$ to insure linearity. The resulting $a_{i j}\left(\tau_{\mathrm{m}}{ }^{*}\right)$ values are of the order $.05-0.1 V_{0 i} / n_{i}$ (Table II). For the more weakly coupled proton pairs, the rise curves reached maximum at larger $\tau_{\mathrm{m}}$, and hence longer $\tau_{\mathrm{m}}^{*}(\sim 2.2-5 \mathrm{~ms})$ could be used. The $\sigma_{i} s$ resulting from eq 5 are listed in Table II. For the known geminal proton pairs, the $\sigma_{i j}$ ranges from 38.3 to $58.6 \mathrm{~s}^{-1}$ for an average $49.0 \pm 10.5$. We use this average as reference for the relative $\sigma_{i j}$ values for the proton pairs in Table II and, since $r_{i j} \propto \sigma_{i j}^{-1 / 6}$, obtain relative $r_{i j}$ values for all proton pairs. By setting $r_{i j}=1.77 \AA$ for the average geminal $\sigma_{i j}=49.0 \mathrm{~s}^{-1}$, the relative $r_{i j}$ leads to estimates of $r_{i j}$ for all proton pairs, as listed in Table II. For the likely rigid four methylene groups, this yields $r_{i j}$ in the range $1.72-1.85 \AA$.

The rise curves for the fixed geometry $\delta$-meso- $\mathrm{H} \rightarrow 8-\mathrm{CH}_{3}$ (Figure 5A) and $\alpha$-meso-H $\rightarrow 3-\mathrm{CH}_{3}$ (Figure 4B) exhibit very similar slopes, indicating that they reflect very similar $\sigma_{i j}, r_{i j}$, as is expected; the $5-\mathrm{CH}_{3}$ and $\beta$-meso-H resonate too close to each other ${ }^{26}$ under the diamagnetic envelope to allow the characterization of a rise curve. Since 3-CH $\mathrm{CH}_{3}$ yields NOEs to both the $\alpha$-meso-H peak (not shown) and a partially overlapping resonance, ${ }^{4,5}$ a quantitative $\sigma_{i j}$ was obtainable only from $\delta$-meso$\mathrm{H} \rightarrow 8-\mathrm{CH}_{3}$. The observed $\left|\sigma_{i j}\right| \sim 3.2 \mathrm{~s}^{-1}$, which yields $r_{i j} \sim 2.8$ $\AA$, is very close to that expected for this fixed geometry, $2.85 \AA$. Thus the "calibration" data for the heme and known geminal protons dictate that relative distance can be quantitatively determined using the very short linear portions of the rise curves. The relative cross relaxation rates and distances for several pairs of strongly relaxed protons ${ }^{42}$ whose geometry depends on the orientation of side chains are obtained from the linear portion of the rise curves and the values listed in Table II. For the axial His 170 , distances $2.1-2.2 \AA$ are obtained for $\mathrm{C}_{\beta} \mathrm{H}^{\prime}: \mathrm{N}_{\mathrm{P}} \mathrm{H}$ and $\mathrm{C}_{\beta} \mathrm{H}: \mathrm{C}_{\alpha} \mathrm{H}$. The $r\left(4 \mathrm{H}_{\alpha}: \beta\right.$-meso-H $)$ is estimated at $2.2 \AA$, as shown in Table II.

The estimated $\sigma_{i j}$ for the three methylene groups that can reasonably be expected to be immobile within the protein matrix, the $\mathrm{His} \mathrm{C}_{\beta} \mathrm{H}: \mathrm{C}_{\beta} \mathrm{H}^{\prime}$, propionate $7 \mathrm{H}_{\alpha}: 7 \mathrm{H}_{\alpha}{ }^{\prime}$, and $\mathrm{Arg} 38 \mathrm{C}_{\beta} \mathrm{H}: \mathrm{C}_{\beta} \mathrm{H}^{\prime}$, is $49 \pm 10 \mathrm{~s}^{-1}$, and using $r_{i j}=1.77 \AA$ translates to a correlation time $\tau_{\mathrm{c}}=27 \pm 5 \mathrm{~ns}$ by eq 2 . This value compares reasonably

(42) Each dipolar set of protons $i, j$ gives rise to two NOESY cross peaks which, under sufficiently slow pulse recycle times, are equal in intensity. However, if $i, j$ have different $T_{1}$ s, the rapid pulsing conditions employed here can lead to suppression of the cross peak at the $f_{1}$ frequency of the slower relaxing resonance (Williamson, M. P.; Neuhaus, D. J. Magn. Reson. 1987 $72,369-375$ ). The difference in cross peak intensities for $\alpha$-substituents is $<20 \%$ and hence does not significantly contribute to uncertainties in $\sigma_{l j}$; for differences of $>10 \%$, only the larger value was used to obtain distance. Larger differences in cross peak intensities are observed for $\beta$-substituents, and hence no attempts were made to extract $\sigma_{b j}$.

(43) The Arg $38 \mathrm{C}_{\delta} \mathrm{H}, \mathrm{C}_{\delta} \mathrm{H}^{\prime}$ geminal pair yielded a well-defined rise curve based on peak height (Figure 3 ), but the base line artifacts precluded the determination of the peak volumes. 
Table II. Cross Relaxation Rates and Distances Determined in HRP-CN from NOESY Cross Peak Intensity ${ }^{a}$

\begin{tabular}{|c|c|c|c|c|c|c|c|c|}
\hline residue & proton pairs $i \rightarrow j$ & $a_{i j}\left(\tau_{\mathrm{m}}^{*}\right)^{b}$ & $\tau_{\mathrm{m}}^{*}, \mathrm{~ms}$ & $\left|\sigma_{i j}\right|, \mathrm{s}^{-1} \mathrm{c}$ & rel $r_{i f} f$ & $\operatorname{rel} r_{i j}, e$ & $r_{i j} f \AA$ & expected $r_{i j}, \AA$ \\
\hline \multirow[t]{2}{*}{ His 170} & $\mathrm{C}_{\beta} \mathrm{H} \rightarrow \mathrm{C}_{\beta} \mathrm{H}^{\prime}$ & 2.83 & 1.5 & 44.8 & 0.90 & 1.02 & 1.81 & 1.77 \\
\hline & $\mathrm{C}_{\beta} \mathrm{H}^{\prime} \rightarrow \mathrm{C}_{\beta} \mathrm{H}$ & 3.57 & 1.5 & 56.5 & 1.14 & 0.98 & 1.73 & 1.77 \\
\hline \multirow[t]{2}{*}{ Arg 38} & $\mathrm{C}_{\beta} \mathrm{H} \rightarrow \mathrm{C}_{\beta} \mathrm{H}^{\prime}$ & 3.67 & 1.5 & 58.1 & 1.17 & 0.97 & 1.72 & 1.77 \\
\hline & $\mathrm{C}_{\beta} \mathrm{H}^{\prime} \rightarrow \mathrm{C}_{\beta} \mathrm{H}$ & 2.65 & 1.5 & 42.0 & 0.84 & 1.03 & 1.82 & 1.77 \\
\hline \multirow[t]{3}{*}{ Heme } & $7 \mathrm{H}_{\alpha} \rightarrow 7 \mathrm{H}_{\alpha}^{\prime}$ & 2.42 & 1.5 & 38.3 & 0.77 & 1.04 & 1.85 & 1.77 \\
\hline & $7 \mathbf{H}_{\alpha}^{\prime} \rightarrow 7 \mathbf{H}_{\alpha}$ & 3.70 & 1.5 & 58.6 & 1.18 & 0.97 & 1.72 & 1.77 \\
\hline & $\delta$-meso- $\mathrm{H} \rightarrow 8-\mathrm{CH}_{3}$ & 1.20 & 3.0 & 3.2 & 0.064 & 1.58 & 2.80 & 2.85 \\
\hline \multirow[t]{3}{*}{ His 170} & $\mathrm{C}_{\alpha} \mathrm{H} \rightarrow \mathrm{C}_{\beta} \mathrm{H}$ & 1.33 & 2.2 & 14.4 & 0.29 & 1.23 & 2.18 & \\
\hline & $\mathrm{N}_{\mathrm{p}} \mathrm{H} \rightarrow \mathrm{C}_{\beta} \mathrm{H}^{\prime}$ & 1.59 & 2.2 & 17.2 & 0.35 & 1.19 & 2.11 & \\
\hline & $\mathrm{C}_{\beta} \mathrm{H}^{\prime} \rightarrow \mathrm{N}_{\mathrm{p}} \mathrm{H}$ & 1.40 & 2.2 & 15.1 & 0.30 & 1.22 & 2.16 & \\
\hline heme & $\beta$-meso- $4 \mathrm{H}_{\alpha}$ & 1.29 & 2.2 & 13.9 & 0.28 & 1.23 & 2.18 & \\
\hline
\end{tabular}

a $3 \mathrm{mM}$ in ${ }^{2} \mathrm{H}_{2} \mathrm{O}, \mathrm{pH} 7.0$ at $35^{\circ} \mathrm{C} .{ }^{b}$ Volume of cross peak (in arbitrary units, but the same as for diagonal, $V_{0 i} / n_{i}=42.1$ ) for mixing time $\tau_{\mathrm{m}}{ }^{*}($ longest $\tau_{\mathrm{m}}$ where rise curve is linear); uncertainty $\pm 15 \%$. ${ }^{c}$ Cross relaxation rate, $\sigma_{i j}$, obtained via eq 5 ; uncertainty $\pm 30 \%$. ${ }^{d}$ Relative $\sigma$, obtained by scaling $\sigma$ value obtained via eq 5 by the mean $\sigma$ for the known four geminal pair data, $\bar{\sigma}\left(\mathrm{CH}_{2}\right)=49.0 \mathrm{~s}^{-1}$. ${ }^{e} \operatorname{Rel} r_{i j}=(\text { rel } \sigma)^{1 / 6}$, via eq 2 ; uncertainty $\pm 5 \%$. $f$ Obtained from rel $r_{i j}$ using $r_{i j}=1.77 \AA$ for geminal protons; uncertainty $\pm 5 \%$.
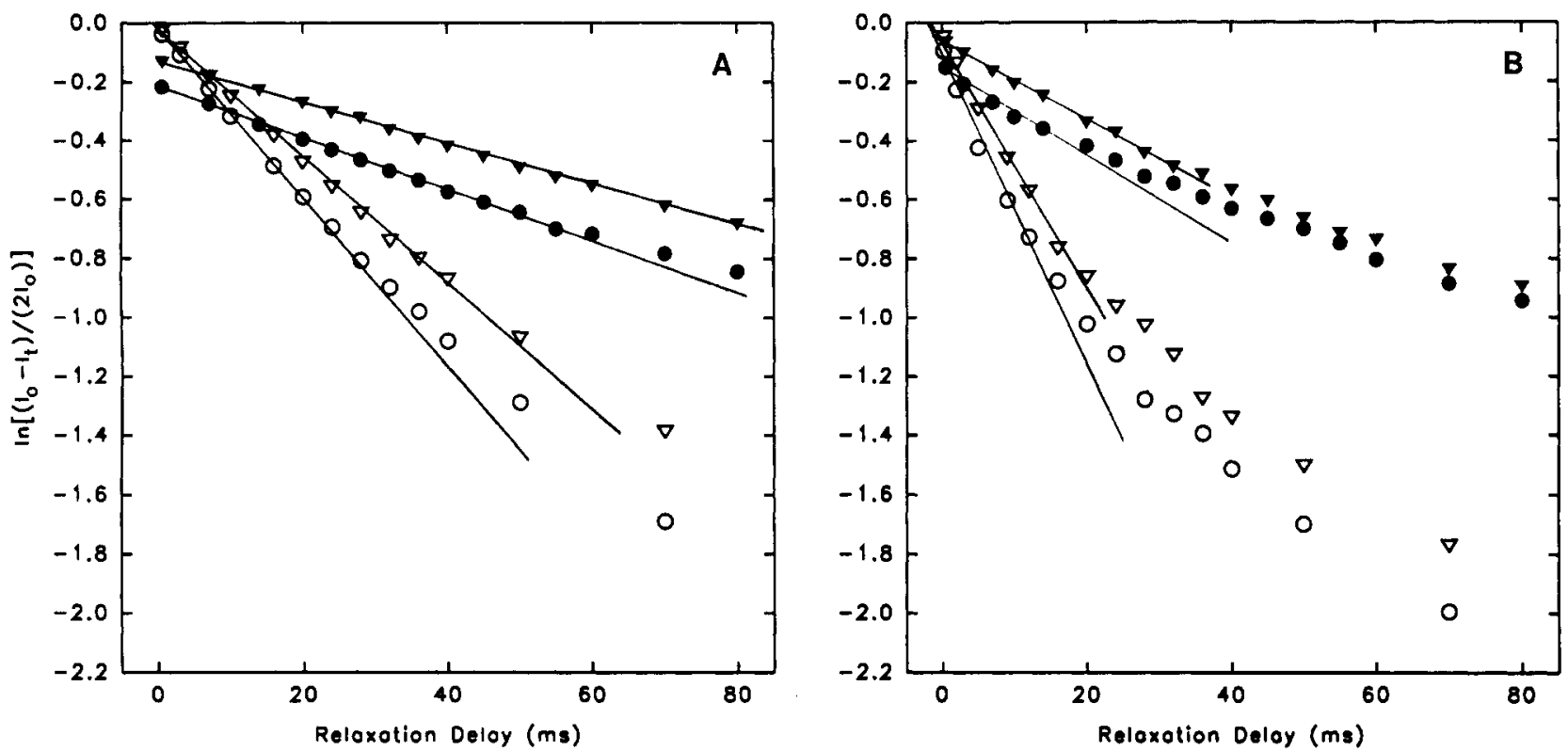

Figure 7. Semilogarithmic plots of fractional recovered intensity vs relaxation delay, $\tau$, for nonselective inversion-recovery data (solid markers) and selective saturation-recovery data (open markers). (A) Plots for $8-\mathrm{CH}_{3}(\bullet$ and $\mathrm{O})$ and $3-\mathrm{CH}_{3}(\nabla$ and $\nabla$ ), and (B) plots for His $170 \beta(\bullet$ and 0$)$ and His $170 \beta^{\prime}(\nabla$ and $\nabla)$. Note that only the initial portions of the plots are linear and that the selective data show greater slope (larger $p$ ).

well with that estimated by the Stokes-Einstein equation for a $44-\mathrm{kDa}$ globular protein ${ }^{12}(22 \mathrm{~ns})$ and that estimated from the quadrupolar relaxation ${ }^{44}$ of deuterium-labeled HRP-CN $(28 \mathrm{~ns})$. The use of the $\tau_{c}$ from the Stokes-Einstein equation, together with the observed $\sigma_{i j}$, yields a geminal $r_{i j}=1.72-\AA$ separation. Thus we conclude that the initial rise curves for a paramagnetic low-spin ferric heme peroxidase or similar sized hemoprotein can be used to estimate absolute distances, in particular those distances that will uniquely identify geminal protons.

Relaxation Rates. In Figure 7 we present the semilogarithmic plots for the recovery of magnetization versus relaxation delay time, $\tau$, for nonselective $\left(\rho^{\text {nsel }}=\left(T_{1}^{\text {nsel }}\right)^{-1}\right)$ and selective $\left(\rho^{\text {sel }}=\right.$ $\left.\left(T_{1} \text { sel) }\right)^{-1}\right)$ ) experiments for the heme $8-\mathrm{CH}_{3}$ and $3-\mathrm{CH}_{3}$ peaks (panel $\mathrm{A}$ ) and the axial $\mathrm{His} \mathrm{C}_{\beta} \mathrm{H}$ and $\mathrm{C}_{\beta} \mathrm{H}^{\prime}$ peaks (panel B). It is clear that the recoveries are not single exponential ${ }^{37}$ and that computer fits to straight lines over an arbitrary long time will yield $\rho$ (or $T_{1}$ ) estimates that are much slower (longer) than the initial slopes. The initial slopes yield relaxation rates as listed in Table I, where similar data for the other resolved peaks are also included. The initial slope was generally maintained only for a time shorter than the $T_{1}=\rho^{-1}$ determined from the initial slope. The degree of curvature in the plots varies significantly for the resolved resonances, with the largest observed for geminal proton pairs. Difference in $T_{1}{ }^{\text {nsel }}$ patterns from those reported

(44) La Mar, G. N.; Thanabal, V.; Johnson, R. D.; Smith, K. M.; Parish, D. W. J. Biol, Chem. 1989, 264, 5428-5434. earlier ${ }^{5,26}$ is due to the earlier failure to emphasize data collection at much shorter times. Note that the nonselective $T_{1}$ s are virtually useless for predicting the mixing time for optimal cross peak intensity. The selective saturation magnetization recovery curves in Figure 7 exhibit substantially steeper slopes and larger $\rho s$ (shorter $T_{1} \mathrm{~s}$ ); after a time interval $\sim T_{1}$ sel, significant curvature that could yield longer $T_{1}{ }^{\text {sel }}$ estimates by a computer least-squares fit is also apparent. In general, $\rho^{\text {sel }}$ is longer than $\rho^{\text {nsel }}$ by factors between 2 and 10 , which emphasizes that the simpler nonselective $T_{1}$ data cannot substitute for the $T_{1}$ sel. The correlation between $\left(\rho^{\text {sel }}\right)^{-1}$ and $\tau_{\mathrm{m}}$ at maximum cross peak intensity is much better than that for the $\left(\rho^{\text {nsel }}\right)^{-1}$, as should be expected. ${ }^{10-12}$

Another measure of the intrinsic relaxation rate is provided by the initial rate of the decay of the diagonal intensity with mixing time in a NOESY experiment. ${ }^{10-12,38}$ The diagonal intensity is given by: ${ }^{10-12}$

$$
a_{i i}\left(\tau_{\mathrm{m}}\right)=\frac{V_{0 i}\left|\sigma_{i j}\right|}{2 D}\left(1+\mathrm{e}^{-2 D \tau_{\mathrm{m}}}\right) \mathrm{e}^{-(R-D) \tau_{\mathrm{m}}}
$$

which, for very short $\tau_{\mathfrak{m}} \ll\left(2 D^{-1}\right),(R-D)^{-1}$, yields:

$$
a_{i i}\left(\tau_{\mathrm{m}}\right)=V_{0 i} \frac{\left|\sigma_{i j}\right|}{D}\left(1-R_{i} \tau_{\mathrm{m}}\right)
$$

where $R_{i}$ is the effective relaxation rate and $V_{0 i}$ is the equilibrium magnetization (diagonal volume at $\tau_{\mathrm{m}}=0$ ). Plots of $a_{i i}$ vs $\tau_{\mathrm{m}}$ 
were found linear for $\tau_{\mathrm{m}}$ to $\sim 3 \mathrm{~ms}$ and the resulting slopes listed as $R_{i}$ in Table I. $R_{i}$ and $\rho_{i}^{\text {sel }}$ differ significantly primarily for geminal protons, for which $R_{i}$ is generally larger than $\rho_{i}^{\text {sel }}$ by a factor of 1.3-1.7. It is noteworthy, however, that it is $R_{i}^{-1}$ that correlates best with the $\tau_{\mathrm{m}}$ for the maximum intensity of a cross peak.

Steady-State NOEs. Steady-state NOE measurements for HRP-CN have been reported at $55^{\circ} \mathrm{C}$, where the lines are narrowers and resolution, particularly in the upfield portion, is significantly improved. $4,5,25$ We report here only representative steady-state NOEs at the present temperature of interest, $35^{\circ} \mathrm{C}$, in order to provide a comparison of distances obtained by $1 \mathrm{D}$ and 2D NOE methodology. Saturation of the axial $\mathrm{His} \mathrm{C}_{\beta} \mathrm{H}$ and $\mathrm{C}_{\beta} \mathrm{H}^{\prime}$ signals yields the steady-state NOEs $\eta\left(\mathrm{C}_{\beta} \mathrm{H} \rightarrow \mathrm{C}_{\beta} \mathrm{H}^{\prime}\right)=$ $-0.68 \pm 0.07$ and the reciprocal value, $\eta\left(\mathrm{C}_{\beta} \mathrm{H}^{\prime} \rightarrow \mathrm{C}_{\beta} \mathrm{H}\right)=-0.53$ \pm 0.06 . The selective relaxation rates for these two signals given in Table I yield ${ }^{14}\left|\sigma_{i j}\right|=38 \pm 4$ and $39 \pm 4 \mathrm{~s}^{-1}$, respectively, via eq 4 . The use of the nonselective relaxation rates in Table I, on the other hand, yields cross relaxation rates of $\sim 10 \pm 1 \mathrm{~s}^{-1}$ in each case.

\section{Discussion}

Evaluation of NOESY Data. The present NOESY data on HRP-CN reveal that it is indeed possible to obtain reliable and quantitative rise curves that discriminate between primary and secondary NOEs and provide a sufficient initial linear portion to obtain both the relative and an estimate of the absolute cross relaxation rates for a variety of proton pairs that reasonably closely correlate with known values. While the commonly used 20-ms mixing time in isoelectronic, isostructural complexes $26-29,33,34$ provides a good single value that allows observation of the majority of the primary NOEs, a large number of secondary NOEs are also observed which could lead to incorrect assessments of proximity between proton pairs. the crucial limitation to both the differentiation of primary and secondary NOEs and the quantification of an initial linear portion to obtain distance is sensitivity. The practicality of this study, which in all entailed nearly 20 NOESY maps, each requiring $10 \mathrm{~h}$, was facilitated by the availability of sufficient protein to provide a $3 \mathrm{mM}$ sample to adequately fill a $10-\mathrm{mm}$ tube. Comparison of sensitivity characteristics of this $10-\mathrm{mm}$ probe with a state-of-the-art $5-\mathrm{mm}$ ${ }^{1} \mathrm{H}$ probe indicates that the NOESY spectrum is obtainable in $20 \mathrm{~h}$ per $\tau_{\mathrm{m}}$ value in the latter probe, which is not significantly larger than the data collection time needed for a diamagnetic system. The inherently lower intensity of cross peaks in the paramagnetic system is offset, in large part, by the ability to use a significantly shorter pulse sequence repetition time (i.e., $\sim 1.5$ $T_{1} \mathrm{~s} \sim 200 \mathrm{~ms}$ ), allowing a much larger number of scans per block than for a comparable diamagnetic system. ${ }^{3}$ However, the faster repetition rate also will cause saturation of some hyperfine shifted protons such as $\beta$-protons on the heme (vinyl, propionate $\mathrm{H}_{\beta} \mathrm{s}$ ), precluding the determination of reliable distances involving these protons from the present data. ${ }^{42}$

Valuable qualitative information obtained from the detailed rise curves and not obtainable from the most commonly used $\tau_{\mathrm{m}}$ $\sim 20-30 \mathrm{~ms}$ is stereospecific assignments of methylene groups. Thus, the primary NOE $7-\mathrm{H}_{\alpha} \rightarrow 8-\mathrm{CH}_{3}$ and secondary NOE $7 \mathrm{H}_{\alpha}{ }^{\prime} \rightarrow 8-\mathrm{CH}_{3}$ and the His 170 primary NOE $\mathrm{C}_{\beta} \mathrm{H} \rightarrow \mathrm{C}_{\alpha} \mathrm{H}$ and secondary NOE $C_{\beta} \mathrm{H}^{\prime} \rightarrow \mathrm{C}_{\alpha} \mathrm{H}$ differentiate the $7-\alpha$-methylene and His 170 methylene protons, respectively. Such stereospecific assignments will be valuable for the detailed analysis of dipolar shifts in terms of the magnetic axes of the heme iron. ${ }^{45}$ The present study indicates that NOESY data should allow the stereospecific assignments and determination of detailed stereochemistry relative to the heme of key noncoordinated catalytic

(45) Emerson, S. D.; La Mar, G. N. Biochemistry 1990, 29, 1556-1566 Rajarathnam, K.; La Mar, G. N.; Chiu, M. L.; Sligar, S. G. J. Am. Chem. Soc. 1992, 114, 9048-9058. residues in the heme pocket. $5,25,26$ Such studies, however, must involve further extensions of scalar correlation experiments, ${ }^{2,26}$ as well as improvements of the NOESY spectra to minimize the artifacts in the diamagnetic region, ${ }^{39,40}$ since the resonances from noncoordinated residues, while hyperfine shifted, generally exhibit shifts insufficient to resolve a significant number of peaks outside the diamagnetic envelope. Such studies to address these problems are in progress.

In the absence of bond correlation spectra, the NOESY cross peak intensities can clearly identify immobile methylene groups. At mixing times of $0.5-2.0 \mathrm{~ms}$, they dominate the NOESY map and provide enough intensity to allow a semiquantitative estimate of $\sigma_{i j}$ and hence $r_{i j}$; other proton pairs exhibit $<20 \%$ of the intensity of geminal pairs in this linear region. Conversely, NOESY maps collected at $>30 \mathrm{~ms}$ do not necessarily allow a distinction between geminal and nongeminal proton pairs. This is because the intrinsic relaxation rate for methylene protons is so much faster than that suggested by nonselective $T_{1} \mathrm{~s}$ that the cross peaks will have decayed significantly and do not necessarily exceed that for a more weakly coupled proton pair with slower intrinsic relaxation rate. Certainly the nonselective $T_{1}$ s do not directly provide useful information for selecting an optimal mixing time for a low-spin heme peroxidase; selective $T_{1}$ s serve as a more appropriate basis (Table I). The reason for this is that cross relaxation can easily exceed the paramagnetic contribution to the relaxation process (see below).

Orientation of Side Chains. The NOESY rise curves provide more definitive information on structure than steady-state NOEs and single mixing time NOESY spectra. The cis orientation of the 4-vinyl and the trans orientation of the 2-vinyl group, previously proposed on the basis of limited data, 4,26 are quantitatively confirmed. However, the 2-vinyl $\mathrm{H}_{A t} \rightarrow 3-\mathrm{CH}_{3} \mathrm{NOE}$, previously judged primary ${ }^{4}$ by time-dependent $1 \mathrm{DNOEs}$, is shown to be secondary, and the pathway for this transfer is shown to proceed $2 \mathrm{H}_{\beta t} \rightarrow \alpha-$ meso- $\mathrm{H} \rightarrow 3-\mathrm{CH}_{3}$. The reason for this misinterpretation of the ID NOEs, and a basic limitation of ID NOEs of any type on a paramagnetic system, ${ }^{3,46}$ is that the time needed to sufficiently saturate a resonance limits times for investigation to $>10 \mathrm{~ms}$. The secondary NOE is shown here to develop in less than half this time. A molecular model of protohemin clearly shows that in any trans orientation, the $2-\mathrm{H}_{\hat{\rho t}}$ will always be closer to $\alpha$-meso-H than $3-\mathrm{CH}_{3}$. For the cis-oriented 4-vinyl group, the $2.2-\AA 4 \mathrm{H}_{\alpha}: \beta$-meso-H distance, together with the molecular modeling of these two distances as a function of the vinyl/heme dihedral angle, suggests an angle of $45 \pm 20^{\circ}$ for the 4-vinyl group. ${ }^{47}$ It is interesting that, while solution ${ }^{1} \mathrm{H}$ NMR has indicated 2-vinyl/4-vinyl trans/cis orientations in lignin peroxidase ${ }^{27,28}$ and all derivatives of HRP, 4,48 the orientation for the two vinyls in $\mathrm{C} c \mathrm{P}^{21,22}$ are cis and trans for the 2-vinyl and 4-vinyl group, respectively.

The NOE pattern among the vicinal protons of the 7-propionate group (Figure $5 \mathrm{~B}$ ) dictates an orientation with very similar disposition of $7 \mathrm{H}_{\alpha}: 7 \mathrm{H}_{\beta}$ and $7 \mathrm{H}_{\alpha}{ }^{\prime}: 7 \mathrm{H}_{\beta}{ }^{\prime}$ pairs, i.e., the $\mathrm{H}_{\alpha}-\mathrm{C}_{\alpha-}$ $\mathrm{C}_{\beta}-\mathrm{H}_{\beta}$ and $\mathrm{H}_{\alpha}^{\prime}-\mathrm{C}_{\alpha}-\mathrm{C}_{\beta}-\mathrm{H}_{\beta}^{\prime}$ dihedral angles $\theta$ are both either $\sim 0^{\circ}$ or $\sim 60^{\circ}$. However, the $\cos ^{2} \theta$ dependence of scalar coupling ${ }^{49}$ and the previous observation ${ }^{26}$ of intense COSY peaks only for the proton pairs $7 \mathrm{H}_{\alpha}-7 \mathrm{H}_{\beta}{ }^{\prime}$ and $7 \mathrm{H}_{\alpha}{ }^{\prime}-7 \mathrm{H}_{\beta}$ dictate that the propionate chain is extended (i.e., $\mathrm{H}_{\alpha}-\mathrm{C}_{\alpha}-\mathrm{C}_{\beta}-\mathrm{H}_{\beta}$ and $\mathrm{H}_{\alpha}^{\prime}-$ $\mathrm{C}_{\alpha}-\mathrm{C}_{\beta}-\mathrm{H}_{\beta}^{\prime}$ dihedral angles each $\sim 60^{\circ}$ ) with the carboxylate group pointed away from the heme rather than toward the iron. The axial His 170 NOESY cross peak rise curves reveal an orientation with $\mathrm{C}_{\beta} \mathrm{H}$ closer to $\mathrm{C}_{\alpha} \mathrm{H}$ and $\mathrm{C}_{\beta} \mathrm{H}^{\prime}$ closer to the $\mathrm{N}_{\mathrm{P}} \mathrm{H}$, with the large hyperfine shifted $\mathrm{C}_{\beta} \mathrm{H}$ closer to $\mathrm{C}_{\alpha} \mathrm{H}$; these two

(46) Lecomte, J. T. J.; Unger, S. W.; La Mar, G. N. J. Magn. Reson. 1991, $94,112-122$.

(47) The dihedral angle is defined as $0^{\circ}$ for an in-plane, cis orientation.

(48) Thanabal, V.; de Ropp, J. S.; La Mar, G. N. J. Am. Chem. Soc. 1986, $108,4244-4245$.

(49) Karplus, M. J. Chem. Phys. 1959, 30, 11-15. 
distances are estimated at $\sim 2.1-2.2 \AA$. The axial His 175 in the $\mathrm{C} c \mathrm{P}-\mathrm{CN}$ crystal structure ${ }^{21,22}$ reveals a similar orientation with one $\mathrm{C}_{\beta} \mathrm{H}$ close to $\mathrm{N}_{\mathrm{P}} \mathrm{H}$ and the other closer to $\mathrm{C}_{\alpha} \mathrm{H}$; the observed distances are 2.6 and $2.3 \AA$, revealing a very similar but not identical orientation of the axial His side chain with respect to the helical backbone.

Relaxation Studies. In a macromolecule exhibiting cross relaxation, the recovery of magnetization is not a single exponential ${ }^{3,37}$ and a " $T_{1}$ " can only be extracted from the initial linear portion of a semilogarithmic plot of $I-I_{0}$ as a function of time. A spin $i$ with magnetic moment $I$, with intrinsic relaxation rate $\rho_{i}$ (both diamagnetic and paramagnetic contributions) interacting with spins $j$ with magnetic moment $J$ via cross relaxation $\sigma_{i j}$, obeys the equation:12,37

$$
\frac{\mathrm{d} I}{\mathrm{~d} t}=-\rho_{i}\left(I-I_{0}\right)-\sum^{j} \sigma_{i j}\left(J-J_{0}\right)
$$

The initial linear portions of a nonselective and selective $T_{1}$ experiment yield recovery rates, respectively:

$$
\begin{gathered}
\rho_{i}^{\text {nsel }}=\rho_{i}+\sum^{j} \sigma_{i j} \\
\rho_{i}^{\text {sel }}=\rho_{i}
\end{gathered}
$$

The intrinsic relaxation rate has both diamagnetic and paramagnetic components, ${ }^{3,37} \rho_{i}=\rho_{i}$ (dia) $+\rho_{i}$ (para). Since $\sigma_{i j}$ is negative for a macromolecule, ${ }^{12}$ we always have $\rho^{\text {sel }}>\rho^{\text {nsel }}$, as observed in Table I. Because $\sigma_{i j}$ s are so large in a large macromolecule (approaching $\left.-\rho_{i}(\text { dia })^{12}\right), \rho^{\text {sel, }}, \rho^{\text {nsel }}$ diverge strongly as a macromolecule increases in size. While nonselective $T_{1} \mathrm{~s}$ may approximate intrinsic $T_{1} \mathrm{~s}$ in a small molecule (or in a molecule where the paramagnetic contribution to $\rho_{i}$ is much larger than $\left.\sum \sigma_{i j}\right)$, the correlation fails in large molecules with only moderate paramagnetic contribution to $\rho_{i}$, such as low-spin heme perox-

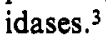

In Table I we list $\rho f^{\text {sel }}$ measured by saturation recovery, $R_{i}$ obtained from NOESY diagonal decay, ${ }^{10,38}$ the nonselective $\rho_{A}^{\text {nsel }}$, and the differences $\Delta \rho_{i}=\rho_{i}^{\text {sel }}-\rho_{i}^{\text {nsel }}$ and $\Delta \rho_{i}^{\prime}=R_{i}-\rho_{i}^{\text {nsel }}$. Also included are the ratios $\rho^{\text {sel }} / \rho^{\text {nsel }}$. For a relatively isolated proton such as the distal $\mathrm{His} 42 \mathrm{C}_{t} \mathrm{H}$ in ${ }^{2} \mathrm{H}_{2} \mathrm{O}$, the difference in relaxation rates is small, which is consistent with the detection of only a few relatively weak NOEs. ${ }^{5}$ On the other hand, for all geminal partners, $\Delta \rho_{i}=\rho_{i}^{\text {sel }}-\rho_{i}^{\text {nsel }}$ equals or slightly exceeds $\sigma_{i j}$ to its geminal partner. Thus the difference in selective and nonselective relaxation rates finds a ready correlation with the degree of cross relaxation experienced by a proton. ${ }^{3,12}$ From the practical side these observations have two consequences. Nonselective $T_{1}$ values will be useless for estimating optimal NOESY mixing times or interpreting steady-state NOEs (see below). However, a possible use of $\rho^{\text {sel }}, \rho^{\text {nsel }}$ is to identify geminal proton pairs in larger paramagnetic macromolecules by inspecting the difference in $\rho^{\text {sel }}$ and $\rho^{\text {nsel }}$ for signals that approach the expected geminal $\sigma$ for the particular sized protein.

For selection of $\tau_{\mathrm{m}}$ for optimal sensitivity for NOESY cross peaks, $R_{i}^{-1}$ obtained by decay of the NOESY diagonal is the appropriate indicator.$^{10-12}$ However, the selection of $\tau_{\mathrm{m}}$ can still be optimized prior to embarking on potentially very long $2 \mathrm{D}$ data collection. Since the diagonal peaks are typically 1 order of magnitude more intense than any cross peak in the linear regime, a fast set of NOESY spectra to estimate $R_{i}$ can be collected at the rapid pulsing rate with minimal scans ( 32 scans as opposed to the 352 needed for data in Figure 2), reducing the data collection time by a factor $\geq 10$.

Interpretation of Steady-State NOEs. The His $\mathrm{C}_{\beta} \mathrm{H}: \mathrm{C}_{\beta} \mathrm{H}^{\prime}$ steady-state NOE data yield ${ }^{14}\left|\sigma_{i j}\right| \sim 40 \pm 4 \mathrm{~s}^{-1}$ using the selective relaxation rate for the respective signals, which is in reasonable agreement with the values $\left(\sim 49 \pm 10 \mathrm{~s}^{-1}\right)$ determined by the NOESY cross peak rise curves. One likely reason for the smaller $\sigma_{i j}$ from steady-state NOEs than NOESY cross peaks is that steady state is not achieved for $50-100 \mathrm{~ms}$, and during this time multiple secondary NOEs develop and the two spin approximations become invalid. The NOESY-determined cross relaxation rates are all derived from data collected at very short $\tau_{\mathrm{m}}(1.5-3.0$ $\mathrm{ms}$ ), which is generally before any secondary NOEs are observed. The relationship between $\rho^{\text {sel }}$ and $\rho^{\text {nsel }}$, as it relates to interpretation of steady-state NOEs, is not their difference but their ratio, $\rho^{\text {sel } /}$ $\rho^{\text {nsel }}$, which is included in Table II. The use of the nonselective relaxation rates in determining $\sigma_{i j}$ for the $\mathrm{His} \mathrm{C}_{\beta} \mathrm{Hs}$ via eq 4 , on the other hand, yields values that seriously underestimate the cross relaxation rates (by a factor $~ 4-6$ ) and hence significantly overestimate distance (by $\sim 30 \%$ ). The degree that steady-state NOE interpretations of $\sigma_{i j}$ are incorrect by using nonselective versus selective relaxation rates is given by the factor $\rho^{\mathrm{sel}} / \rho^{\text {nsel }}$ listed in Table I. For nongeminal proton pairs for which the ratio $\rho^{\text {sel }} / \rho^{\text {nsel }}$ is particularly large $\left(i . e ., 4 \mathrm{H}_{\alpha}, 3 \mathrm{CH}_{3}\right)$, distances obtained using $\rho^{\text {nsel }}$ would result in substantial errors in $r_{i j}$. Hence, while steady-state NOEs clearly demand the use of the selective rather than the nonselective relaxation rate, the use of the proper rate appears to yield distances that are similar to those obtained from NOESY data.

Acknowledgment. The authors are indebted to A. D. McPherson for experimental assistance. M. Sette is grateful to M.U.R.S.T. for a fellowship to carry out these studies. This research was supported by a grant from the National Institutes of Health, GM 26226, and the NMR spectrometer was purchased, in part, by funds provided by the National Institutes of Health, RR-04795, and the National Science Foundation, BBS-88-04739. 